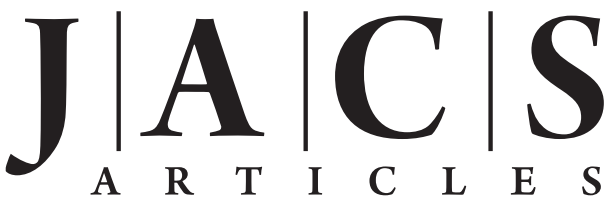

Published on Web 07/17/2009

\title{
Ordered and Oriented Supramolecular n/p-Heterojunction Surface Architectures: Completion of the Primary Color Collection
}

\author{
Ravuri S. K. Kishore, ${ }^{\dagger}$ Oksana Kel, ${ }^{\ddagger}$ Natalie Banerji, ${ }^{\ddagger}$ Daniel Emery, ${ }^{\dagger}$ \\ Guillaume Bollot, ${ }^{\dagger}$ Jiri Mareda, ${ }^{\dagger}$ Alberto Gomez-Casado, "Pascal Jonkheijm, \\ Jurriaan Huskens, ${ }^{\natural}$ Plinio Maroni, ${ }^{\S}$ Michal Borkovec, ${ }^{\S}$ Eric Vauthey, ${ }^{*, \neq}$ \\ Naomi Sakai, ${ }^{*, \dagger}$ and Stefan Matile ${ }^{*, \dagger}$ \\ Departments of Organic, Inorganic and Analytical, and Physical Chemistry, University of \\ Geneva, Geneva, Switzerland, and Molecular Nanofabrication Group, University of Twente,
} Enschede, The Netherlands

Received April 23, 2009; E-mail: eric.vauthey@unige.ch; naomi.sakai@unige.ch; stefan.matile@unige.ch

\begin{abstract}
In this study, we describe synthesis, characterization, and zipper assembly of yellow p-oligophenyl naphthalenediimide (POP-NDI) donor-acceptor hybrids. Moreover, we disclose, for the first time, results from the functional comparison of zipper and layer-by-layer (LBL) assembly as well as quartz crystal microbalance (QCM), atomic force microscopy (AFM), and molecular modeling data on zipper assembly. Compared to the previously reported blue and red NDIs, yellow NDIs are more $\pi$-acidic, easier to reduce, and harder to oxidize. The optoelectronic matching achieved in yellow POP-NDIs is reflected in quantitative and long-lived photoinduced charge separation, comparable to their red and much better than their blue counterparts. The direct comparison of zipper and LBL assemblies reveals that yellow zippers generate more photocurrent than blue zippers as well as LBL photosystems. Continuing linear growth found in QCM measurements demonstrates that photocurrent saturation at the critical assembly thickness occurs because more charges start to recombine before reaching the electrodes and not because of discontinued assembly. The found characteristics, such as significant critical thickness, strong photocurrents, large fill factors, and, according to AFM images, smooth surfaces, are important for optoelectronic performance and support the existence of highly ordered architectures.
\end{abstract}

\section{Introduction}

Directional energy, electron and hole transport along sophisticated multicomponent donor-acceptor cascades, is essential in biological photosynthesis. ${ }^{1}$ In bilayer organic solar cells, electrons and holes generated by exciton dissociation at the interface of $\mathrm{n}$ - and $\mathrm{p}$-semiconductors travel through gradient-free bulk layers. ${ }^{2 a}$ In bulk $\mathrm{n} / \mathrm{p}$-heterojunction (BHJ) solar cells, the active interface is increased to maximize the efficiency of exciton dissociation. ${ }^{2-5}$ Improved exciton dissociation at increased interfaces usually comes at the cost of decreased hole and electron mobility in less continuous and organized $n-$ and p-semiconducting materials. To achieve

\footnotetext{
$\dagger$ Department of Organic Chemistry, University of Geneva.

Department of Physical Chemistry, University of Geneva.

${ }^{\S}$ Department of Inorganic and Analytical Chemistry, University of Geneva.

${ }^{\pi}$ Molecular Nanofabrication Group, University of Twente.

(1) (a) Deisenhofer, J.; Michel, H. Science 1989, 245, 1463-1473. (b) Nelson, N.; Ben-Shem, A. Nat. Rev. Mol. Cell Biol. 2004, 5, 971982. (c) Carmeli, I.; Frolov, L.; Carmeli, C.; Richter, S. J. Am. Chem. Soc. 2007, 129, 12352-12353. (d) Barber, J. Chem. Soc. Rev. 2009, $38,185-196$.

(2) (a) Tang, C. W. Appl. Phys. Lett. 1986, 48, 183-185. (b) Yu, G.; Gao, J.; Hummelen, J. C.; Wudl, F.; Heeger, A. J. Science 1995, 270, 17891791. (c) Thompson, B. C.; Fréchet, J. M. J. Angew. Chem., Int. Ed. 2008, 47, 58-77. (d) Gnes, S.; Neugebauer, H.; Sariciftci, N. S. Chem. Rev. 2007, 107, 1324-1338.
}

efficient exciton dissociation without losses in charge mobility, bicontinuous electron- $\left(\mathrm{e}^{-}\right)$and hole $\left(\mathrm{h}^{+}\right)$-transporting channels that are aligned coaxially on the molecular level are desired. This ideal architecture has been referred to as supramolecular n/p-heterojunction (SHJ). Contrary to the advanced situation with covalent donor-acceptor architectures, ${ }^{6}$ synthetic "bottom-up" access to $\mathrm{SHJs}^{7-10}$ remains, however, as challenging as the installation of redox gradients. ${ }^{11-16}$ In the bioinspired ideal scenario, electrons and holes generated by photoinduced charge separation (PCS) would be rapidly carried away in opposite directions along oriented multicolored antiparallel redox gradients (OMARGs) in the adjacent n- and p-channels of SHJs. Ideal OMARGSHJ architectures can be expected to give not only maximal short circuit photocurrents but also maximal fill factors ${ }^{5 a}$ as well as open circuit voltages ${ }^{11,14 a}$ (see below).

(3) (a) Lee, J. K.; Ma, W. L.; Brabec, C. J.; Yuen, J.; Moon, J. S.; Kim, J. Y.; Lee, K.; Bazan, G. C.; Heeger, A. J. J. Am. Chem. Soc. 2008, 130, 3619-3623. (b) Yang, X.; Loos, J.; Veenstra, S. C.; Verhees, W. J. H.; Wienk, M. M.; Kroon, J. M.; Michels, M. A. J.; Janssen, R. A. J. Nano Lett. 2005, 5, 579-583.

(4) Ma, C.; Fonrodona, M.; Schikora, M. C.; Wienk, M. M.; Janssen, R. A. J.; Bäuerle, P. Adv. Funct. Mater. 2008, 18, 3323-3331.

(5) (a) Yang, F.; Shtein, M.; Forrest, S. Nat. Mater. 2005, 4, 37-41. (b) O'Regan, B.; Grätzel, M. Nature 1991, 353, 737-741. 


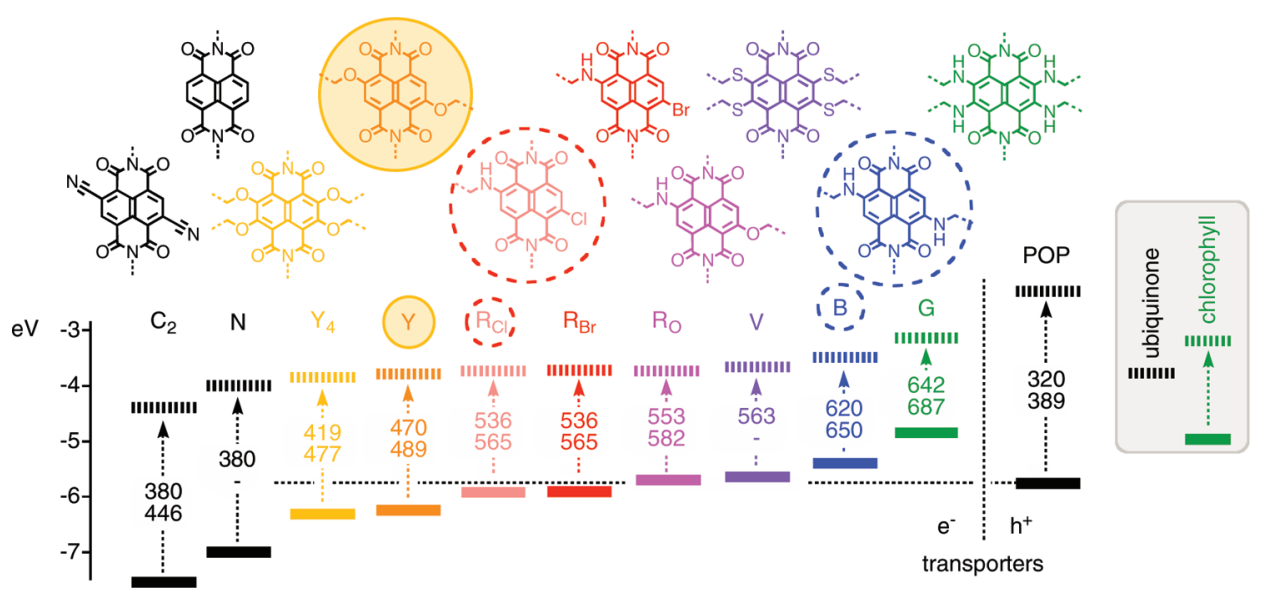

Figure 1. Frontier orbital energy levels of NDIs (general structures $\mathrm{C}_{2}-\mathrm{G}$ ), POPs (general structure as in Figure 2), chlorophyll, and ubiquinone (solid lines, HOMO; dashed lines, LUMO); dashed arrows, absorption of light $(h v)$ with wavelength (nm) of maximal absorption (top) and emission (bottom); data from refs $20-24,33$, and this report.

Recently, we have introduced zipper assembly as a new approach toward OMARG-SHJs and other applications in

(6) (a) Balzani, V.; Venturi, M.; Credi, A. Molecular Devices and Machines; Wiley-VCH: Weinheim, Germany, 2003. (b) Fukuzumi, S. Bull. Chem. Soc. Jpn. 2006, 79, 177-195. (c) Wasielewski, M. R. J. Org. Chem. 2006, 71, 5051-5066. (d) Hambourger, M.; Moore, G. F.; Kramer, D. M.; Gust, D.; Moore, A. L.; Moore, T. A. Chem. Soc. Rev. 2009, 38, 25-35. (e) Martín, N.; Sánchez, L.; Herranz, M. A.; Illescas, B.; Guldi, D. M. Acc. Chem. Res. 2007, 40, 1015-10124. (f) Clifford, J. N.; Gu, T.; Nierengarten, J.-F.; Armaroli, N. Photochem. Photobiol. Sci. 2006, 5, 1165-1172. (g) Imahori, H.; Mori, Y.; Matano, Y. J. Photochem. Photobiol. C: Photochem. Rev. 2003, 4, 51-83.

(7) (a) van der Boom, T.; Hayes, R. T.; Zhao, Y.; Bushard, P. J.; Weiss, E. A.; Wasielewski, M. R. J. Am. Chem. Soc. 2002, 124, 9582-9590. (b) Yamamoto, Y.; Fukushima, T.; Suna, Y.; Ishii, N.; Saeki, A.; Seki, S.; Tagawa, S.; Taniguchi, M.; Kawai, T.; Aida, T. Science 2006, 314 1761-1764. (c) Würthner, F.; Chen, Z.; Hoeben, F. J. M.; Osswald, P.; You, C.-C.; Jonkheijm, P.; Herrikhuyzen, J.; Schenning, A. P. H. J.; van der Schoot, P. P. A. M.; Meijer, E. W.; Beckers, E. H. A.; Meskers, S. C. J.; Janssen, R. A. J. J. Am. Chem. Soc. 2004, 126, 10611-10618. (d) Yamamoto, Y.; Fukushima, T.; Saeki, A.; Seki, S.; Tagawa, S.; Ishii, N.; Aida, T. J. Am. Chem. Soc. 2007, 129, 9276-9277.

(8) Sakai, N.; Sisson, A. L.; Bürgi, T.; Matile, S. J. Am. Chem. Soc. 2007, 129, 15758-15759.

(9) Sisson, A. L.; Sakai, N.; Banerji, N.; Fürstenberg, A.; Vauthey, E.; Matile, S. Angew. Chem., Int. Ed. 2008, 47, 3727-3729.

(10) (a) Kira, A.; Umeyama, T.; Matano, Y.; Yoshida, K.; Isoda, S.; Park, J. K.; Kim, D.; Imahori, H. J. Am. Chem. Soc. 2009, 131, 3198-3200 (b) Snaith, H. J.; Whiting, G. L.; Sun, B.; Greenham, N. C.; Huck, W. T. S.; Friend, R. H. Nano Lett. 2005, 5, 1653-1657.

(11) Sista, S.; Yao, Y.; Yang, Y.; Tang, M. L.; Bao, Z. Appl. Phys. Lett. 2007, 91, 223508/1-223508/3.

(12) (a) Yamada, H.; Imahori, H.; Nishimura, Y.; Yamazaki, I.; Ahn, T. K.; Kim, S. K.; Kim, D.; Fukuzumi, S. J. Am. Chem. Soc. 2003, 125, 9129-9139. (b) Takeda, T.; Lin, C.; Majima, T. Angew. Chem., Int. Ed. 2007, 46, 6681-6683. (c) Kimura, S. Org. Biomol. Chem. 2008, 6, 1143-1148.

(13) (a) Mwaura, J. K.; Pinto, M. R.; Witker, D.; Ananthakrishnan, N.; Schanze, K. S.; Reynolds, J. R. Langmuir 2005, 21, 10119-10126. (b) Fushimi, T.; Oda, A.; Ohkita, H.; Ito, S. Langmuir 2005, 21, 15841589. (c) Zhao, L.; Ma, T.; Bai, H.; Lu, G.; Li, C.; Shi, G. Langmuir 2008, 24, 4380-4387.

(14) (a) Abdelrazzaq, F. B.; Kwong, R. C.; Thompson, M. E. J. Am. Chem. Soc. 2002, 124, 4796-4803. (b) Lahav, M.; Heleg-Shabtai, V.; Wasserman, J.; Katz, E.; Willner, I.; Dürr, H.; Hu, Y.-Z.; Bossmann, S. H. J. Am. Chem. Soc. 2000, 122, 11480-11487.

(15) (a) Guldi, D. M. J. Phys. Chem. B 2005, 109, 11432-11441. (b) Martinson, A. B. F.; Massari, A. M.; Lee, S. J.; Gurney, R. W.; Splan, K. E.; Hupp, J. T.; Nguyen, S. T. J. Electrochem. Soc. 2006, 153, A527-A532. (c) Morisue, M.; Yamatsu, S.; Haruta, N.; Kobuke, Y. Chem.-Eur. J. 2005, 11, 5563-5574. (d) Huang, C.-H.; McClenaghan, N. D.; Kuhn, A.; Bravic, G.; Bassani, D. M. Tetrahedron 2006, 62, 2050-2059.

(16) Decher, G. Science 1997, 277, 1232-1237. molecular optoelectronics. ${ }^{8}$ Zipper architectures are composed of $\mathrm{e}^{-}$-transporting $\pi$-stacks aligned along $\mathrm{h}^{+}$-transporting strings of rods. The $\pi$-acidic 1,4,5,8-naphthalenediimides (NDIs) ${ }^{17-26}$ have been selected as $\pi$-stacks in zipper architectures because they can change spectral and redox properties without global structural changes (Figure 1). ${ }^{9,20-23}$ Compared to the many other possible multicolor collections (e.g., perylenediimides, Alexa Fluors, fluoresceins, BODIPYs, cyanines, porphyrinoids, or triangular dehydrobenzo[12] annulenes), ${ }^{27-30}$ the spectacular combination of (1) decreasing HOMO/LUMO energies with increasing HOMO/LUMO energy differences (Figure 1), ${ }^{24-26}$ (2) full coverage of the visible range, (3) global structural preservation, (4) n-semiconductivity, (5) $\pi$-acidity, (6) planarity, (7) compactness ("atom efficiency"), and (8) synthetic accessibility offered by NDIs remains unique. Multicolor redox

(17) (a) Bhosale, S. V.; Jani, C. H.; Langford, S. J. Chem. Soc. Rev. 2008, 37, 331-342. (b) Chaignon, F.; Falkenstrom, M.; Karlsson, S.; Blart, E.; Odobel, F.; Hammarström, L. Chem. Commun. 2007, 42, 64-66. (c) Gao, X.; Qiu, W.; Yang, X.; Liu, Y.; Wang, Y.; Zhang, H.; Qi, T.; Liu, Y.; Lu, K.; Du, C.; Shuai, Z.; Yu, G.; Zhu, D. Org. Lett. 2007, 9, 3917-3920. (d) Lokey, R. S.; Iverson, B. L. Nature 1995, 375, 303-305. (e) Gabriel, G. J.; Iverson, B. L. J. Am. Chem. Soc. 2002, 124, 15174-15175. (f) Pantos, G. D.; Wietor, J. L.; Sanders, J. K. Angew. Chem., Int. Ed. 2007, 46, 2238-2240. (g) Gabutti, S.; Knutzen, M.; Neuburger, M.; Schull, G.; Berndt, R.; Mayor, M. Chem. Commun. 2008, 2370-2372. (h) Iijima, T.; Vignon, S. A.; Tseng, H. R.; Jarrosson, T.; Sanders, J. K. M.; Marchioni, F.; Venturi, M.; Apostoli, E.; Balzani, V.; Stoddart, J. F. Chem.-Eur. J. 2004, 10, 6375-6392. (i) Mukhopadhyay, P.; Iwashita, Y.; Shirakawa, M.; Kawano, S.; Fujita, N.; Shinkai, S. Angew. Chem., Int. Ed. 2006, 45, 1592-1595. (j) Tanaka, H.; Litvinchuk, S.; Tran, D.-H.; Bollot, G.; Mareda, J.; Sakai, N.; Matile, S. J. Am. Chem. Soc. 2006, 128, 16000-16001. (k) Hagihara, S.; Tanaka, H.; Matile, S. J. Am. Chem. Soc. 2008, 130, 5656-5657. (1) Talukdar, P.; Bollot, G.; Mareda, J.; Sakai, N.; Matile, S. J. Am. Chem. Soc. 2005, 127, 6528-6529. (m) Talukdar, P.; Bollot, G.; Mareda, J.; Sakai, N.; Matile, S. Chem.-Eur. J. 2005, 11, 65256532.

(18) (a) Gorteau, V.; Bollot, G.; Mareda, J.; Perez-Velasco, A.; Matile, S. J. Am. Chem. Soc. 2006, 128, 14788-14789. (b) Gorteau, V.; Bollot, G.; Mareda, J.; Matile, S. Org. Biomol. Chem. 2007, 5, 3000-3012.

(19) Mareda, J.; Matile, S. Chem.-Eur. J. 2009, 15, 28-37.

(20) (a) Würthner, F.; Ahmed, S.; Thalacker, C.; Debaerdemaeker, T. Chem.-Eur. J. 2002, 8, 4742-4750. (b) Thalacker, C.; Roger, C.; Würthner, F. J. Org. Chem. 2006, 71, 8098-8105.

(21) Röger, C.; Würthner, F. J. Org. Chem. 2007, 72, 8070-8075.

(22) Blaszczyk, A.; Fischer, M.; von Hänisch, C.; Mayor, M. Helv. Chim. Acta 2006, 89, 1986-2005.

(23) Bhosale, S.; Sisson, A. L.; Talukdar, P.; Fürstenberg, A.; Banerji, N.; Vauthey, E.; Bollot, G.; Mareda, J.; Röger, C.; Würthner, F.; Sakai, N.; Matile, S. Science 2006, 313, 84-86. 

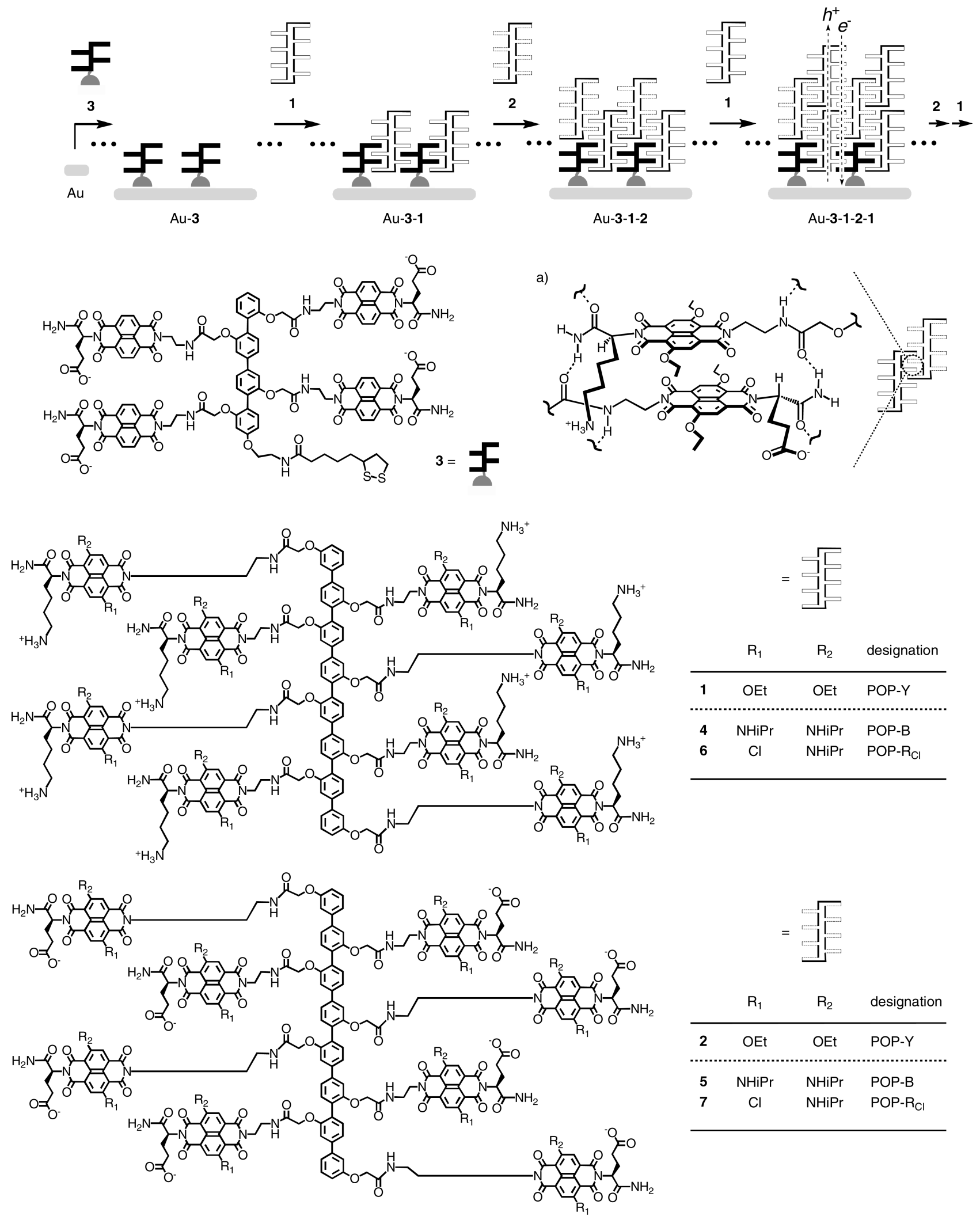

Figure 2. Structure of yellow POP-Y dyads $\mathbf{1}$ and $\mathbf{2}$ and their zipper assembly with initiator $\mathbf{3}$ on gold substrates compared to the structure of the previously reported blue POP-B dyads $\mathbf{4}$ and $\mathbf{5}$ and the red POP-R $\mathrm{R}_{\mathrm{Cl}}$ dyads $\mathbf{6}$ and $\mathbf{7}$ (all suprastructures are speculative representations that are consistent with experimental data, 6 and 7 are mixtures of 2,6- and 3,7-regioisomers). (a) Inter- and intralayer interdigitation of POPs and NDIs, respectively, is thought to be driven by the formation of NDI $\pi$-stacks and controlled by intrastack hydrogen-bonded chains and interstack ion pairing.

gradients obtained with quantum dots appear less suitable because decreasing HOMO with increasing LUMO levels produce low-energy electron traps. ${ }^{31}$
p-Oligophenyls (POPs) have been selected as p-semiconducting $^{32}$ rigid-rod scaffolds in zipper architectures., ${ }^{90-23}$ Zipper assembly of the new yellow POP-NDI hybrids $\mathbf{1}$ and $\mathbf{2}$ begins 
with short $p$-quaterphenyls $\mathbf{3}$. These initiators $\mathbf{3}$ are equipped with anionic NDI acceptors along the scaffold and disulfide tails for covalent immobilization on gold (Figure 2). Incubation of $\mathrm{Au}-\mathbf{3}$ monolayers with cationic $p$-octiphenyl propagators $\mathbf{1}$ is expected to give interdigitating $\mathrm{Au}-\mathbf{3}-\mathbf{1}$ bilayers, where the lower half of the cationic NDIs of propagator $1 \pi$-stacks with the anionic NDI acceptors of initiator $\mathbf{3}$ and the upper half remains free as a "sticky end" to zip up with the lower half of the anionic propagator 2 . The sticky ends in $\mathrm{Au}-\mathbf{3}-\mathbf{1}-\mathbf{2}$ would then be available to zip up with the lower half of cationic propagator 2, and so on. In the resulting POP-NDI zipper architectures $\mathrm{Au}-\mathbf{3}-(\mathbf{1}-\mathbf{2}-)_{n}$, the parallel alignment of $\mathrm{e}^{-}$transporting NDI stacks along strings of $\mathrm{h}^{+}$-transporting POP rods perpendicular to the electrode surface represents the ideal architecture of an SHJ photosystem.

Results with blue zippers $\mathrm{Au}-\mathbf{3}-(\mathbf{4}-\mathbf{5}-)_{n}$ and red zippers $\mathrm{Au}-3-(6-7-)_{n}$ supported the existence of zipper architectures, their functional significance, and their compatibility with OMARG-SHJ architectures (Figure 2). ${ }^{8,9,34}$ However, the HOMO of the blue NDI (B) is too high, and that of the red NDI $\left(\mathrm{R}_{\mathrm{Cl}}\right)$ is barely sufficient to accept electrons from POPs. To improve optoelectronic matching in rod-stack SHJ architectures, either the HOMO of the rod had to be raised or the HOMO of the stack had to be lowered. Yellow NDIs with their low HOMO levels were ideal to explore the latter possibility.

The introduction of yellow zippers was of particular interest to complete the primary color collection of POP-NDI zippers. Their availability would already suffice to build mixed OMARGSHJ architectures that absorb most visible light and have an oriented three-component "blue $\rightarrow$ red $\rightarrow$ yellow" redox gradient in the $\mathrm{e}^{-}$-transporting channel (Figure 1). In the following, we describe the synthesis and complete characterization of yellow POP-NDI zippers. Moreover, for the first time, we directly

(24) Jones, B. A.; Facchetti, A.; Wasielewski, M. R.; Marks, T. J. J. Am. Chem. Soc. 2007, 129, 15259-15278.

(25) (a) Miller, L. L.; Mann, K. R. Acc. Chem. Res. 1996, 29, 417-423. (b) Katz, H. E.; Lovinger, A. J.; Johnson, J.; Kloc, C.; Siegrist, T.; Li, W.; Lin, Y. Y.; Dodabalapur, A. Nature 2000, 404, 478-481. (c) Yan, H.; Chen, Z.; Zheng, Y.; Newman, C.; Quinn, J. R.; Dötz, F.; Kastler, M.; Facchetti, A. Nature 2009, 457, 679-686.

(26) Warman, J. M.; de Haas, M. P.; Dicker, G.; Grozema, F. C.; Piris, J.; Debije, M. G. Chem. Mater. 2004, 16, 4600-4609.

(27) (a) Würthner, F. Chem. Commun. 2004, 1564-1579. (b) Shaller, A. D. Wang, W.; Gan, H.; Li, A. D. Q. Angew. Chem., Int. Ed. 2008, 47, 7705-7709. (c) Perez-Velasco, A.; Gorteau, V.; Matile, S. Angew. Chem., Int. Ed. 2008, 47, 921-923. (d) Peneva, K.; Mihov, G.; Nolde, F.; Rocha, S.; Hotta, J.; Braeckmans, K.; Hofkens, J.; Uji-i, H.; Herrmann, A.; Müllen, K. Angew. Chem., Int. Ed. 2008, 47, 33723375.

(28) (a) Miller, R. A.; Presley, A. D.; Francis, M. B. J. Am. Chem. Soc. 2007, 129, 3104-3109. (b) Koeppe, R.; Bossart, O.; Calzaferri, G.; Sariciftci, N. S. Sol. Energy Mater. Sol. Cells 2007, 91, 986-995.

(29) Haugland, R. P. The Handbook. A Guide to Fluorescent Probes and Labeling Techniques, 10th ed.; Invitrogen: Eugene, OR, 2005.

(30) (a) Rio, Y.; Rodriguez-Morgade, M. S.; Torres, T. Org. Biomol. Chem. 2008, 6, 1877-1894. (b) Tahara, K.; Fujita, T.; Sonoda, M.; Shiro, M.; Tobe, Y. J. Am. Chem. Soc. 2008, 130, 14339-14345. (c) Lopalco, M.; Koini, E. N.; Cho, J. K.; Bradley, M. Org. Biomol. Chem. 2009, 7, 856-859.

(31) (a) Weiss, E. A.; Porter, V. J.; Chiechi, R. C.; Geyer, S. M.; Bell, D. C.; Bawendi, M. G.; Whitesides, G. M. J. Am. Chem. Soc. 2008, 130, 83-92. (b) Kongkanand, A.; Tvrdy, K.; Takechi, K.; Kuno, M.; Kamat, P. V. J. Am. Chem. Soc. 2008, 130, 4007-4015.

(32) Khanna, R. K.; Jiang, Y. M.; Creed, D. J. Am. Chem. Soc. 1991, 113, $5451-5453$.

(33) Sakai, N.; Kishore, R. S. K.; Matile, S. Org. Biomol. Chem. 2008, 6, 3970-3976.

(34) Lista, M.; Sakai, N.; Matile, S. Supramol. Chem. 2009, 21, 238-244.

(35) Banerji, N.; Fürstenberg, A.; Bhosale, S.; Sisson, A. L.; Sakai, N.; Matile, S.; Vauthey, E. J. Phys. Chem. B 2008, 112, 8912-8922.
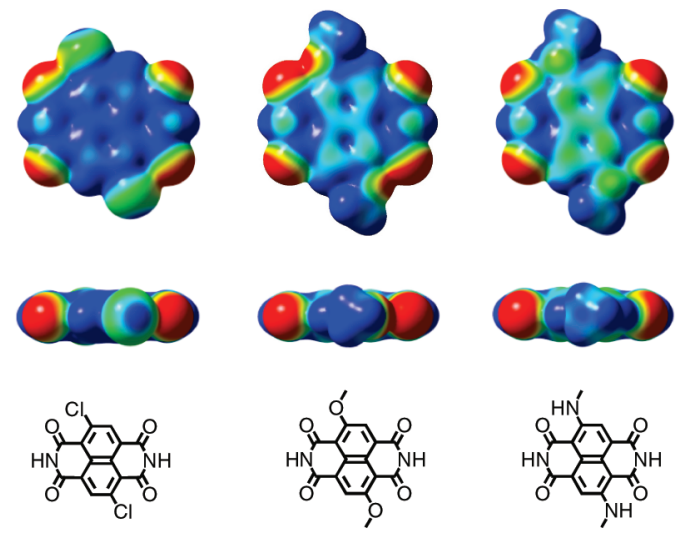

$$
Q_{\mathrm{zz}}=+18.0 \mathrm{~B}
$$

$$
Q_{\mathrm{zz}}=+8.0 \mathrm{~B}
$$

9

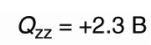

10
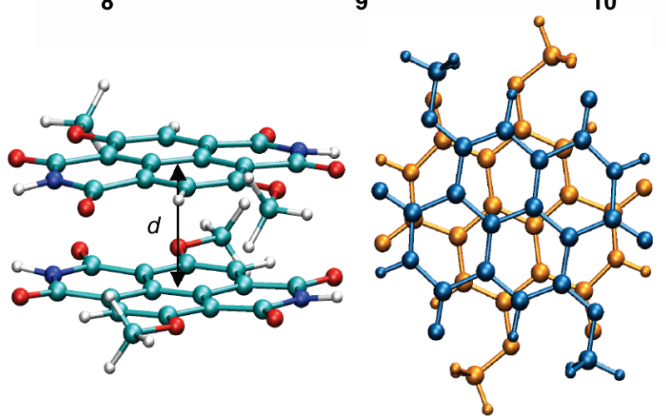

Figure 3. Electrostatic potential surfaces and $Q_{z z}\left(\mathrm{MP} 2 / 6-311 \mathrm{G}^{* *}\right)$ of NDIs 8-10 (top, $\pm 30.0 \mathrm{kcal} / \mathrm{mol}$; blue positive, red negative) and face-to-face dimer of 9 (bottom, $d=3.36 \AA$ ).

compare zipper and layer-by-layer (LBL) assembly and report quartz crystal microbalance (QCM), atomic force microscopy (AFM), and molecular modeling data on zipper assembly.

\section{Results and Discussion}

Molecular Modeling. Dichloro-NDI 8, dimethoxy-NDI 9, and dimethylamino-NDI 10 were selected as tractable model systems to compute the effect of increasingly electron-donating core substituents on the nature of the naphthalene core (Figure 3). Electrostatic potential surfaces were computed using the MP2/ 6-311G** method. ${ }^{36}$ The obtained aromatic surfaces range from weakly positive (light green) with potent diamino $\pi$-donors in 10 and more distinctly positive with the weaker dialkoxy donors in 9 to deep blue with dichloro substituents in $\mathbf{8}$. As expected from crystal structures, ${ }^{37}$ the optimized structures of NDIs were totally planar, independent of the nature of the core substituent.

The global quadrupole moments $Q_{z z}$ of NDIs 8-10 were computed using the MP2/6-311G** method. The $Q_{z z}=+18.0$ $\mathrm{B}$ found for dichloro NDI $\mathbf{8}$ was in the range of unsubstituted NDIs. ${ }^{18 \mathrm{~b}}$ Diamino NDIs 10 remained with $Q_{z z}=+2.3 \mathrm{~B}$, weakly $\pi$-acidic. The $\pi$-acidity of the intermediate dialkoxy NDI 9 was with $Q_{z z}=+8.0 \mathrm{~B}$, close to that of hexafluorobenzene. ${ }^{18}$ The magnitude of this quadrupole moment suggested that, with interdigitating POP-Y dyads $\mathbf{1}$ and $\mathbf{2}$, the conductivity of the resulting $\pi$-stacks could be very high.

(36) (a) Moller, C.; Plesset, M. S. Phys. Rev. 1934, 46, 618-622. (b) Headgordon, M.; Pople, J. A.; Frisch, M. J. Chem. Phys. Lett. 1988, 153, 503-506.

(37) Kishore, R. S. K.; Ravikumar, V.; Bernardinelli, G.; Sakai, N.; Matile, S. J. Org. Chem. 2008, 73, 738-740. 
Scheme $1^{a}$

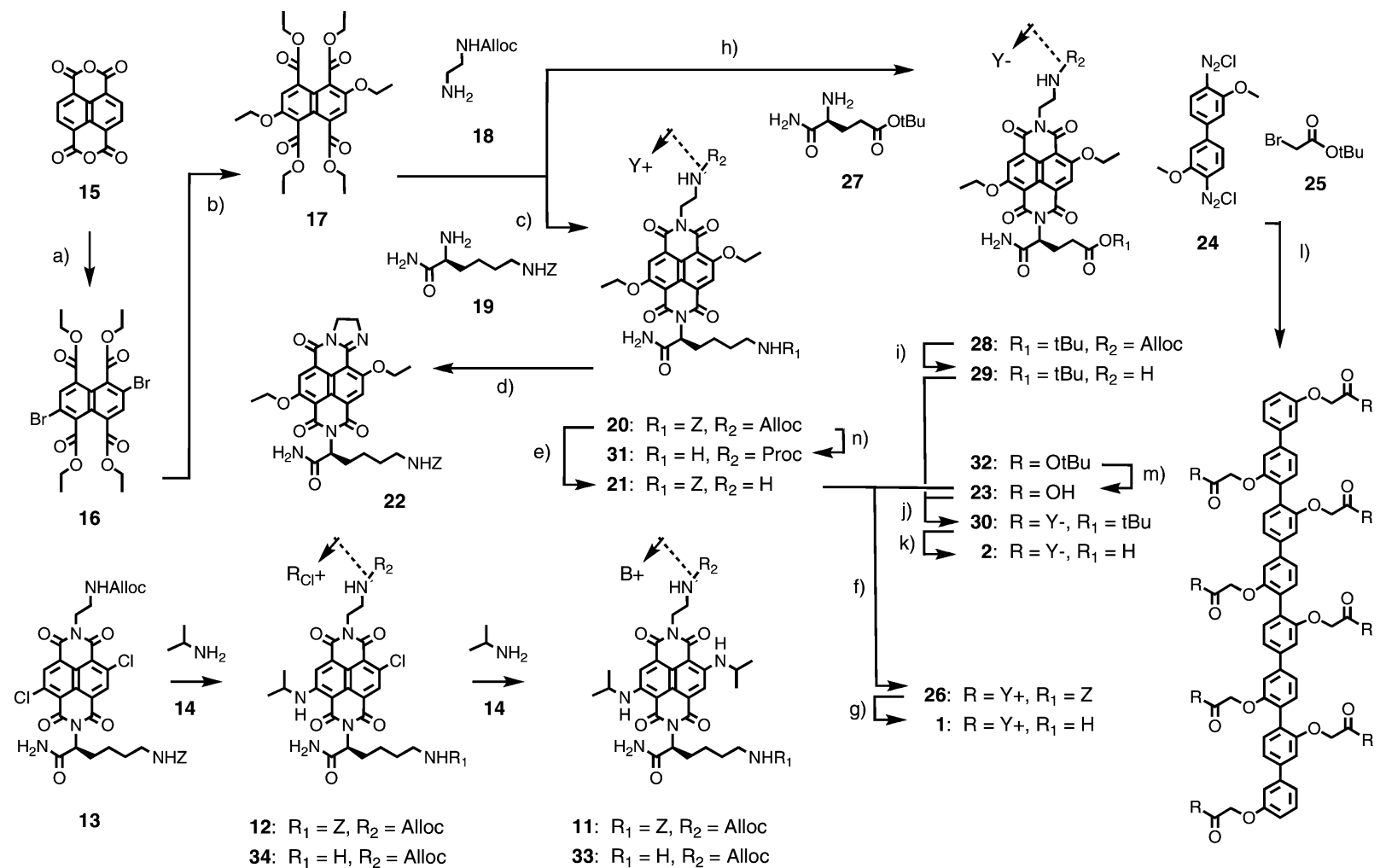

${ }^{a}$ Reagents and conditions: (a) 1. dibromoisocyanuric acid; 2. EtI, EtOH, $\mathrm{K}_{2} \mathrm{CO}_{2}, 35 \% ;{ }^{37}$ (b) NaOEt, $73 \% ;{ }^{37}$ (c) $1 . \mathrm{KOH}, i-\mathrm{PrOH} ; 2 . \mathbf{1 8}, \mathbf{1 9}, \mathrm{AcOH}$, $24 \%$; ${ }^{37}$ (d) $\mathrm{PdCl}_{2}\left(\mathrm{PPh}_{3}\right)_{4}, \mathrm{Bu}_{3} \mathrm{SnH}, p$-nitrophenol; (e) $\mathrm{PdCl}_{2}\left(\mathrm{PPh}_{3}\right)_{4}, \mathrm{PhSiH}_{3}$ (crude); (f) HATU, di-t-Bu-pyridine, TEA, DMF (43\% from 20); (g) HBr/AcOH, TFA, thiophenol, pentamethylbenzene (quant); (h) 1 . KOH, $i$ - $\mathrm{PrOH}$; 2. 18, 27, $\mathrm{AcOH}, 54 \%$; (i) $\mathrm{PdCl}_{2}\left(\mathrm{PPh}_{3}\right)_{4}, \mathrm{PhSiH}_{3}$ (crude); (j) HATU, di-t-Bu-pyridine, TEA, DMF (29\% from 28); (k) TFA, $\mathrm{CH}_{2} \mathrm{Cl}_{2}$ (quant); (1) several steps, as in ref 43; (m) TFA, $\mathrm{CH}_{2} \mathrm{Cl}_{2}\left(\right.$ quant); ${ }^{43}$ (n) $\mathrm{H}_{2}, \mathrm{Pd}(\mathrm{OH})_{2}, \mathrm{MeOH}(\mathrm{quant})$ : Proc $=$ $n$-propyloxycarbonyl.

The strength of the binding was evaluated with methods based on Truhlar's M06-L/6-311G** functional, ${ }^{38}$ which was reported to give very good results for $\pi, \pi$ interactions. ${ }^{39}$ The $\pi, \pi$-stacked dimers of the yellow NDI 9 were therefore optimized with the M06-L functional, and the BSSE-corrected interaction energies were computed at the M06-2X/6-311G** level of theory. The geometry-optimized suprastructure was characterized by a short plane-to-plane distance $d=3.36 \AA$ and a twist of the two aromatic planes by $44^{\circ}$. The strong face-to-face $\pi, \pi$ interactions in $\pi$-stacks implied by the short plane-to-plane distance were confirmed by binding interaction energy of $-27.2 \mathrm{kcal} / \mathrm{mol}$. This value is some $8 \mathrm{kcal} / \mathrm{mol}$ stronger than the value determined for the face-to-face dimers of guanine-cytosine pairs $(-19.0$ $\mathrm{kcal} / \mathrm{mol})^{40}$ and clearly much stronger than that computed for dimers of hexafluorobenzene $(-1.7 \mathrm{kcal} / \mathrm{mol})^{41}$ or benzene $(-2.8 \mathrm{kcal} / \mathrm{mol}){ }^{42}$

Synthesis. The blue NDI 11 and red NDI 12 needed to synthesize POP-B and the red POP-R dyads were obtained by core substitution of 2,6-dichloro-NDIs 13 with isopropylamine 14 (Scheme 1). ${ }^{8,9,20,23}$ This approach did not lead to the yellow POP-Y dyads 1 and 2 because the ethanolate nucleophile was

(38) (a) Zhao, Y.; Truhlar, D. G. Acc. Chem. Res. 2008, 41, 157-167. (b) Zhao, Y.; Truhlar, D. G. J. Chem. Phys. 2006, 125, 194101-194118.

(39) Zhao, Y.; Truhlar, D. G. Theor. Chem. Acc. 2008, 119, 525-525.

(40) Jurecka, P.; Sponer, J.; Cerny, J.; Hobza, P. Phys. Chem. Chem. Phys. 2006, 8, 1985-1993.

(41) Frontera, A.; Quinonero, D.; Costa, A.; Ballester, P.; Deya, P. M. New J. Chem. 2007, 31, 556-560.

(42) Sinnokrot, M. O.; Sherrill, C. D. J. Phys. Chem. A 2006, 110, 1065610668. too reactive and destroyed other functional groups present in the substrate. To address this problem, dianhydride $\mathbf{1 5}$ was brominated with dibromoisocyanuric acid. ${ }^{37}$ Treatment of the product mixture with iodoethane in $\mathrm{EtOH}$ afforded tetraester 16 in overall $35 \%$ yield. Reaction with ethanolate followed by basic hydrolysis of $\mathbf{1 7}$ and reaction of the obtained tetraacid with amines 18 and 19 gave $20 .^{37}$

Chemoselective removal of the Alloc protecting group in $\mathbf{2 0}$ with $\mathrm{Pd}(0)$ and $\mathrm{PhSiH}_{3}$ was problematic because the produced amine 21 cyclized spontaneously into amidine 22 . This problem was bypassed by using the crude amine $\mathbf{2 1}$ without workup. The synthesis of POP 23 from biphenyl 24 and $t$-butyl bromoacetate 25 has been extensively optimized over the past decade. ${ }^{43}$ Reaction of POP 23 with Y 21 and deprotection of the obtained POP-Y conjugate $\mathbf{2 6}$ gave cationic POP-Y dyad $\mathbf{1}$, the first target molecule. The anionic POP-Y dyad 2 was synthesized by reacting the hydrolyzed 17 with the $t$-Buprotected glutamate derivative 27 and amine 18. The obtained NDI 28 was selectively deprotected using Pd catalysis to give amine 29, which in turn was reacted in situ with POP 23. Deprotection of the obtained POP-Y conjugate $\mathbf{3 0}$ gave target molecule 2. The initiator POP-N 3 was synthesized following the previously established synthetic scheme (Figure 2). ${ }^{33}$ The cationic Y monomer 31, needed for control experiments, was readily prepared by hydrogenation/hydrogenolysis of $\mathbf{2 0}$ (Scheme 1).

(43) (a) Sakai, N.; Majumdar, N.; Matile, S. J. Am. Chem. Soc. 1999, 121, 4294-4295. (b) Baumeister, B.; Sakai, N.; Matile, S. Org. Lett. 2001, 3, 4229-4232. 


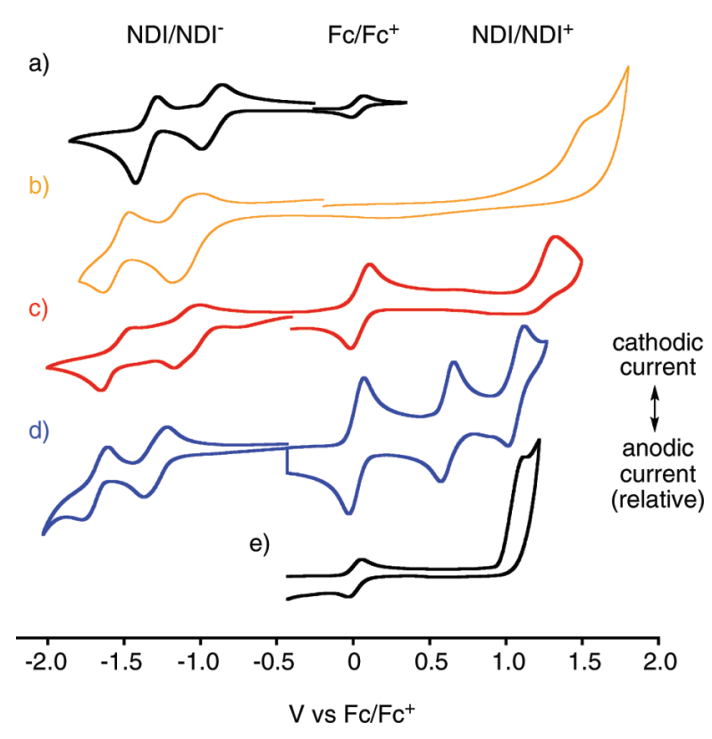

Figure 4. Cyclic voltammograms of (b) Y 20 compared to (a) unsubstituted NDIs (N), ${ }^{33}$ (c) R 12, ${ }^{33}$ (d) B 11, ${ }^{33}$ (e) POP $\mathbf{3 2}^{33}$ and Fc as internal standard.

Cyclic Voltammetry. Redox potentials were determined by cyclic voltammetry $(\mathrm{CV})$ in dichloromethane with the ferrocene/ ferricenium couple $\left(\mathrm{Fc} / \mathrm{Fc}^{+}\right)$as external or internal standard. The first NDI/NDI ${ }^{-}$and the second $\mathrm{NDI}^{-} / \mathrm{NDI}^{2-}$ reduction of Y 20 were both reversible and well detectable (Figure 4b). The redox potential $E_{\text {redl }}^{0}=-1.09 \mathrm{~V}$ for the first NDI/NDI ${ }^{-}$reduction was approximated as midpoint between the separate cathodic and anodic peaks. To calculate the energy level of the LUMO of the Y $\mathbf{2 0}$ against vacuum, the onset of the first reduction potential $E_{\text {red1 }}^{\text {onset }}=-0.98 \mathrm{~V}$ was taken (Table 1, entry 3 ). Subtraction from the $-4.8 \mathrm{eV}$ for the $\mathrm{Fc} / \mathrm{Fc}^{+}$standard gave $E_{\mathrm{LUMO}}=-3.82 \mathrm{eV}$ (Table 1, entry 3, and Figures $4 \mathrm{~b}$ and 1 ). This value was in agreement with reported values for similar compounds. The proposed alternative use of $-5.1 \mathrm{eV}$ for the $\mathrm{Fc} / \mathrm{Fc}^{+}$standard would reduce the value for yellow NDIs correspondingly to $E_{\mathrm{LUMO}}=-4.12 \mathrm{eV} .{ }^{4}$

The redox potential at $E_{\mathrm{ox} 1}^{0}=+1.48 \mathrm{~V}$ for $\mathrm{NDI} / \mathrm{NDI}^{+}$ oxidation was approximated from the oxidation wave; a maximum for the reduction wave as not detectable. The onset of the first oxidation potential $E_{\mathrm{ox} 1}^{\text {onset }}=+1.36 \mathrm{~V}$ corresponded to an $E_{\text {Номо }}=-6.16 \mathrm{eV}$ (Table 1, entry 3 ). The resulting electrochemical HOMO/LUMO gap $E_{\mathrm{g}}^{\mathrm{CV}}=+2.34 \mathrm{eV}$ compared well with the optical HOMO/LUMO gap $E_{\mathrm{g}}^{\text {opt }}=+2.49 \mathrm{eV}$ obtained from the onset of the lowest energy absorption at $\lambda_{\max }^{\text {onset }}$ $=497 \mathrm{~nm}$. Small differences between electrochemical and optical HOMO/LUMO gap are expected not only because of the intrinsic experimental uncertainties but also because charged molecules are compared neutral excited ones. ${ }^{4}$

From the detectable oxidation potential of POP 32, the redox potential for $\mathrm{POP} / \mathrm{POP}^{+}$oxidation was approximated at $E_{\text {red1 }}^{0}=$ $+1.10 \mathrm{~V}$. The onset of the oxidation potential was at $E_{0 \times 1}^{\text {onset }}=$ $+0.95 \mathrm{~V}$ gave $E_{\text {номо }}=-5.75 \mathrm{eV}$ for POPs (Table 1, entry 5 , Figure 4e).

Compared to R 12 and B 11, reduction of Y 20 is easier, whereas oxidation is much harder (Figures $4 \mathrm{~b}-\mathrm{d}$ and 1 ). LUMO and HOMO of Y $\mathbf{2 0}$ remain clearly above those of unsubstituted NDIs N (Figures 4a,b and 1). Y can thus accept electrons from $\mathrm{B}$ and $\mathrm{R}$ and donate electrons to $\mathrm{N}$ (Figure 1).

The HOMO of Y was $\Delta E_{\text {Hомо }}=+0.41 \mathrm{eV}$ below that of POP. This value suggested that PCS in POP-Y dyads should be much more favorable than that in POP-R dyads with $\Delta E_{\mathrm{HOMO}}$ $=+0.16 \mathrm{eV}$ or the disfunctional POP-B dyads with $\Delta E_{\mathrm{HOMO}}$ $=-0.40 \mathrm{eV}$ (Figure 1). Favorable frontier orbital energy levels together with the high electron mobility expected for more electron-deficient NDI stacks implied that POP-Y architectures should afford perfect SHJs.

Steady-State Spectroscopy. The absorption spectra of Y $\mathbf{3 1}$ and POP-Y 1 in MeOH is dominated by a band around $470 \mathrm{~nm}$ due to the NDI $S_{0}-S_{1}$ transition (Figure 5). The energy of this charge transfer type transition depends strongly on the nature of the core substituents (Figures 1 and 5). In POP-Y 1, this band ( $\mathrm{S}_{0} \rightarrow$ NDI-LES (locally excited singlet state)) is substantially broader and slightly red-shifted $\left(\sim 180 \mathrm{~cm}^{-1}\right)$ compared to that of Y 31. A similar effect, which has been ascribed to an excitonic interaction between the chromophoric units, has already been seen with other NDIs on $p$-oligophenyl (POP) and oligophenylethynyl (OPE) scaffolds. ${ }^{35,44}$

The second absorption band centered around $350 \mathrm{~nm}$, with a vibrational progression and observed with all chromophores, is due to a $\pi-\pi^{*}$ transition involving the NDI center. The vibrational progression is not so visible with POP-Y $\mathbf{1}$ as this band overlaps with another one peaking at $320 \mathrm{~nm}$ and originating from the POP scaffold.

The fluorescence spectra of Y $\mathbf{3 1}$ and POP-Y $\mathbf{1}$ upon local NDI excitation are very similar, with a maximum at $489 \mathrm{~nm}$. However, the fluorescence quantum yield, $\Phi_{\mathrm{f}}$, of POP-Y $\mathbf{1}$ is substantially smaller than that of Y $\mathbf{3 1}$ (i.e., 0.008 vs 0.078 ). Interestingly, the fluorescence quantum yield of $Y \mathbf{3 1}$ is close to that of the corresponding $\mathrm{R}_{\mathrm{Cl}}$ monomer $\left(\Phi_{\mathrm{f}}=0.08\right)$ but substantially smaller than that of the B monomer $\left(\Phi_{\mathrm{f}}=0.32\right)$. This reduced yield can be ascribed to the occurrence of intermolecular, hydrogen-bond-assisted nonradiative deactivation. ${ }^{45}$ This process is most probably inhibited in the blue NDI because of the formation of stronger intramolecular hydrogen bonds.

Time-Resolved Fluorescence. The fluorescence decay of $Y$ 31 monomer was recorded using the time-correlated singlephoton counting technique (TCSPC) ${ }^{46}$ Upon excitation at 395 $\mathrm{nm}$ with a $\sim 60$ ps laser pulse, biexponential decay with 2.1 and 7.4 ns lifetimes was obtained (Table 2). Such decay points to the presence of two emitting populations or to a distribution of populations with distinct excited-state lifetimes. This could be due to $\mathrm{H}$ bonds between the alkoxy oxygens and the solvent competing with $\mathrm{H}$ bonding to the carbonyl oxygens. The early fluorescence dynamics of Y $\mathbf{3 1}$ at $490 \mathrm{~nm}$ recorded by fluorescence up-conversion $(\mathrm{FU})^{47}$ exhibits a small additional 28 ps decay component that can be reasonably ascribed to both vibrational and solvent relaxation of the excited state (Figure 6).

The fluorescence decay of POP-Y $\mathbf{1}$ is much faster than that of Y 31, in agreement with the smaller fluorescence quantum yield (Figure 6). Global analysis of the TCSPC and FU profiles requires not less than the sum of five exponential functions with

(44) Banerji, N.; Duvanel, G.; Perez-Velasco, A.; Maity, S.; Sakai, N.; Matile, S.; Vauthey, E. J. Phys. Chem. A, in press.

(45) (a) Flom, S. R.; Barbara, P. F. J. Phys. Chem. 1985, 89, 4489-4494. (b) Fürstenberg, A.; Vauthey, E. Photochem. Photobiol. Sci. 2005, 4, 260-267. (c) Sherin, P. S.; Grilj, J.; Tsentalovitch, Y. P.; Vauthey, E. J. Phys. Chem. B 2009, 113, 4953-4962.

(46) Fürstenberg, A.; Julliard, M. D.; Deligeorgiev, T. G.; Gadjev, N. I.; Vassilev, A. A.; Vauthey, E. J. Am. Chem. Soc. 2006, 128, 76617669.

(47) Morandeira, A.; Engeli, L.; Vauthey, E. J. Phys. Chem. A 2002, 106, $4833-4837$. 
Table 1. Frontier Orbital Energy Levels of $\mathrm{Y}$ from Cyclic Voltammetry $(\mathrm{CV})$ and Absorption Spectroscopy in Comparison to Other NDIs (R, $\mathrm{N}, \mathrm{B})$ and $\mathrm{POPs}^{\mathrm{a}}$

\begin{tabular}{|c|c|c|c|c|c|c|c|c|c|}
\hline entry & $\mathrm{cpd}^{b}$ & $E_{0 \times 1}^{\text {onset }}(\mathrm{V})^{c}$ & $E_{\text {red1 }}^{\text {onset }}(\mathrm{V})^{d}$ & $\lambda_{\max 1}^{\text {onset }}(\mathrm{nm})^{e}$ & $\mathrm{HOMO}(\mathrm{eV})^{f}$ & LUMO $(\mathrm{eV})^{g}$ & $E_{\mathrm{g}}^{\mathrm{CV}}(\mathrm{eV})^{h}$ & $E_{g}^{\mathrm{opt}}(\mathrm{eV})^{i}$ & ref \\
\hline 1 & B & 0.55 & -1.24 & 665 & -5.35 & -3.56 & 1.79 & 1.86 & 33 \\
\hline 2 & $\mathrm{R}$ & 1.11 & -1.02 & 570 & -5.91 & -3.78 & 2.13 & 2.18 & 33 \\
\hline 3 & $\mathrm{Y}$ & 1.36 & -0.98 & 497 & -6.16 & -3.82 & 2.34 & 2.49 & \\
\hline 4 & $\mathrm{~N}$ & nd & -0.81 & 405 & $-7.07^{j}$ & -4.01 & nd & 3.06 & 33 \\
\hline 5 & POP & 0.95 & nd & 365 & -5.75 & $-2.35^{k}$ & nd & 3.40 & 33 \\
\hline
\end{tabular}

${ }^{a}$ For original data and conditions, see Figures 4 and $5 .{ }^{b}$ Measured for monomeric yellow NDI 20 and the corresponding NDI analogues, and POP 32; for generic and specific structures, see Figure 1, Scheme 1, and references. ${ }^{c}$ Onset value of the first oxidation potential in volts against $\mathrm{Fc} / \mathrm{Fc}{ }^{+}$. ${ }^{d}$ Onset value of the first reduction potential in volts against $\mathrm{Fc} / \mathrm{Fc}^{+} .{ }^{e}$ Onset wavelength of the longest wavelength absorption. ${ }^{f}$ Energy of the highest occupied molecular orbital against vacuum, from $-4.8 \mathrm{eV}$ for $\mathrm{Fc} / \mathrm{Fc}^{+}$minus $E_{\mathrm{oxl}}^{\text {onset. }}{ }^{g}$ Energy of the lowest unoccupied molecular orbital against vacuum, from $-4.8 \mathrm{eV}$ for $\mathrm{Fc} / \mathrm{Fc}^{+}$minus $E_{\mathrm{redl}}^{\text {onset }} .{ }^{h}$ Electrochemical HOMO/LUMO gap $E_{\mathrm{g}}^{\mathrm{CV}}(\mathrm{eV})=\mathrm{LUMO}-\mathrm{HOMO} .{ }^{i} \mathrm{Optical} \mathrm{HOMO} / \mathrm{LUMO}$ gap $E_{\mathrm{g}}^{\mathrm{opt}}(\mathrm{eV})=$ $1240 / \lambda_{\max 1}^{\text {onset }}(\mathrm{nm}) .{ }^{j}$ From LUMO $-E_{\mathrm{g}}^{\mathrm{opt}} .{ }^{k}$ From HOMO $+E_{\mathrm{g}}^{\mathrm{opt}}$.

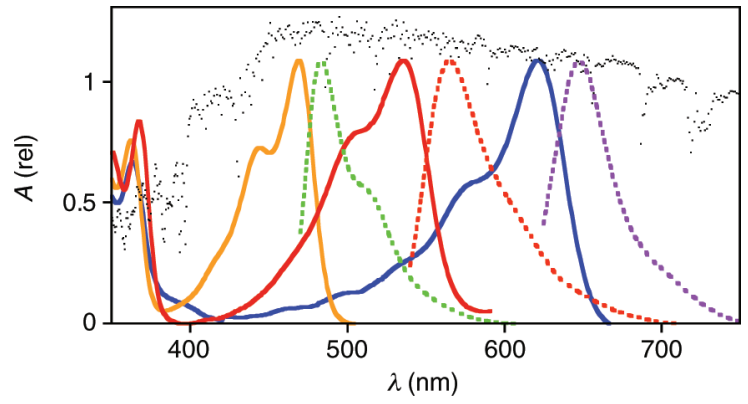

Figure 5. Absorption and emission spectra of Y $\mathbf{3 1}$ (yellow and green) in $\mathrm{MeOH}$ compared to the corresponding $\mathrm{R}_{\mathrm{Cl}}$ (red), ${ }^{35} \mathrm{~B}$ (blue and violet), ${ }^{35}$ and air mass (AM) 1.5 solar spectral irradiance.

time constants ranging from about 1 ps to 5.5 ns (Table 2). The fluorescence dynamics of POP- $\mathrm{R}_{\mathrm{Cl}}$ and POP-B are also multiexponential, but the associated time constants exhibit a narrower dispersion. ${ }^{35}$ However, the relative amplitudes of the smaller decay rate constants measured with POP-Y are very small, indicative of very efficient nonradiative deactivation pathways of the LES.

Transient Absorption Spectroscopy. Information on the origin of the ultrafast nonradiative deactivation of POP-Y $\mathbf{1}$ was obtained from the transient absorption (TA) spectra recorded upon $400 \mathrm{~nm}$ excitation (Figure 7A). ${ }^{48}$ The TA spectra consist of a positive band located between 470 and $570 \mathrm{~nm}$. The shape of this band exhibits substantial changes during the first $10 \mathrm{ps}$ after excitation. The intensity on its long wavelength side decreases, whereas that on the high wavelength side increases. From 10 ps onward, the band shape stays essentially unchanged but decreases on the 100 ps time scale to a value that remains almost constant within the time window of the experiment. These initial spectral changes can be ascribed to an intramolecular charge separation (CS) in the POP-Y dyad. Indeed, the red side of the TA band recorded at early time can be ascribed to the absorption of the LES, whereas its blue side and the band measured after 10 ps can be assigned to a charge-separated state (CSS). This interpretation is comforted by the $S_{1}$ state absorption spectrum measured with monomer Y 31 in $\mathrm{MeOH}$ and by the spectrum of Y radical anion, recorded with Y $\mathbf{3 1}$ in the presence of the electron donor, $N, N$-dimethylaniline (DMA, Figure 7B).

Whereas in the CSS the electron is on a NDI unit, the location of the hole, the POP scaffold, or another NDI chromophore cannot be deduced from the TA spectra. As discussed in ref $35 \mathrm{POP}^{\circ+}$ is expected to absorb weakly around $450 \mathrm{~nm}$. Moreover, spectroelectrochemical measurements performed with

(48) Duvanel, G.; Banerji, N.; Vauthey, E. J. Phys. Chem. A 2007, 111, 5361. the $\mathrm{B}$ and $\mathrm{R}_{\mathrm{Cl}}$ monomers reveal that both anion and cation have similar absorption spectra.

However, energetic considerations point to a CSS with the hole on the POP scaffold. Indeed, according to the Weller equation, ${ }^{49}$ and using the redox potentials of $\mathrm{Y}$ monomer and POP together with a value of $2.6 \mathrm{eV}$ for the energy of the LES, the driving force of the photoinduced CS between two yellow NDIs amounts to $-0.03 \mathrm{eV}$ only, whereas that for the CS between the POP scaffold and a yellow NDI is $-0.41 \mathrm{eV}$. Thus, even if CS to between two NDIs is operative, that with the POP can be expected to be much faster. Furthermore, even if the NDI/NDI CSS is populated, hole transfer from the $\mathrm{NDI}^{\cdot+}$ to the POP should be expected.

The presence of slow decay components observed by timeresolved fluorescence as well as a contribution of the LES population to the late TA spectra of POP-Y indicates that the time scales of CS and CR are partially overlapping, and therefore, the $\mathrm{CR}$ dynamics cannot be directly extracted from the decay of the NDI anion TA band. This situation is similar to that encountered with red POP- $\mathrm{R}_{\mathrm{Cl}}$, and therefore, the same procedure, described in detail in ref 35 , has been used to extract the intrinsic CR dynamics of POP-Y. Figure 8 shows the TA profile of POP-Y $\mathbf{1}$ at $500 \mathrm{~nm}$ after removal of the contribution arising from the LES population, the latter being determined from the fluorescence time profile. ${ }^{35}$ This trace thus reflects the temporal dependence of the CSS population. The continuous line is the best fit of eq 1 in ref 35, which is a convolution of the intrinsic CR dynamics with the buildup rate of the CSS population. The CSS profile could be wellreproduced assuming a biexponential CR with $200 \mathrm{ps}$ and $>5$ ns time constants and with 0.73 and 0.27 relative amplitudes.

The CR dynamics of POP-Y $\mathbf{1}$ is quite similar, although slightly slower, to that found with red POP- $\mathrm{R}_{\mathrm{Cl}}$ and much slower than that of blue POP-B (Figure 8). This difference can be unambiguously attributed to the nature of the CSS. For energetic reasons, only the NDI/NDI CSS can be populated in the POP$\mathrm{B}$, whereas both NDI/NDI and POP/NDI CSS are accessible with POP- $\mathrm{R}_{\mathrm{Cl}}$ and POP-Y. The longer-lived POP/NDI CSS can be explained by a superior spatial confinement of the charges as already discussed. ${ }^{35}$ On the other hand, the similar CR dynamics of POP-Y and POP- $\mathrm{R}_{\mathrm{Cl}}$ are in agreement with their almost identical driving force.

Zipper and LBL Assembly. Freshly cleaned gold electrodes were dipped into $1 \mathrm{mM}$ solutions of POP-N 3 in aqueous TFE in the presence of $500 \mathrm{mM} \mathrm{NaCl}$ and $0.5 \mathrm{mM}$ phosphate buffer of $\mathrm{pH} 7.0$, at ambient temperature for 1 week. ${ }^{8,9,33,34}$ Initiation kinetics were followed by photocurrent generation (Figures 9

(49) Rehm, D.; Weller, A. Isr. J. Chem. 1970, 8, 259-271. 
Table 2. Fluorescence Decay and Quantum Yield of $Y$ and POP-Ya

\begin{tabular}{|c|c|c|c|c|c|c|c|c|c|c|c|c|c|}
\hline entry & $\mathrm{cpd}$ & $\tau_{\dagger 1}$ & $A_{f 1}$ & $\tau_{\uparrow 2}$ & $\mathrm{~A}_{\mathrm{t} 2}$ & 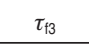 & $\mathrm{A}_{\mathrm{f3}}$ & $\tau_{\ddagger 4}$ & $\mathrm{~A}_{i 4}$ & $\tau_{45}$ & $\mathrm{~A}_{45}$ & $<\tau_{f}>^{c}$ & $\Phi_{\mathrm{f}}$ \\
\hline 1 & 31 & $28 \mathrm{ps}$ & $0.12^{b}$ & $2.1 \mathrm{~ns}$ & 0.74 & $7.4 \mathrm{~ns}$ & 0.14 & & & & & $2.59 \mathrm{~ns}$ & 0.078 \\
\hline 2 & 1 & $0.54 \mathrm{ps}$ & 0.27 & $4.1 \mathrm{ps}$ & 0.39 & $37 \mathrm{ps}$ & 0.21 & $2.2 \mathrm{~ns}$ & 0.12 & $5.5 \mathrm{~ns}$ & 0.01 & $319 \mathrm{ps}$ & 0.008 \\
\hline
\end{tabular}

${ }^{a}$ Time constants $\tau$ with relative amplitudes $A$ were obtained from the global analysis of the fluorescence time profiles of Y $\mathbf{3 1}$ and POP-Y 1. ${ }^{b}$ This component is not due to the decay of the excited-state population (see text). ${ }^{c}$ Amplitude-averaged lifetime.

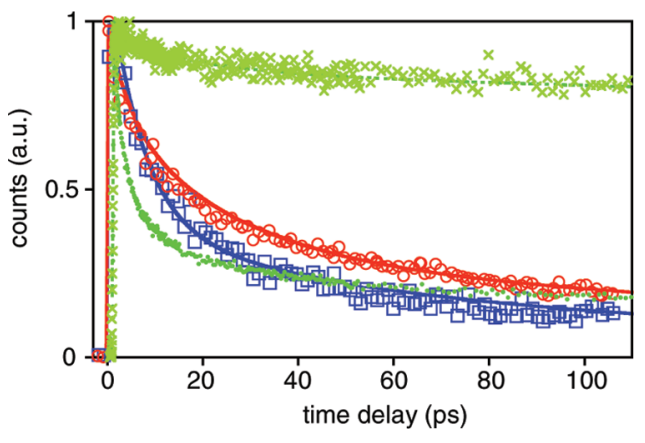

Figure 6. Intensity-normalized time profiles of the fluorescence intensity of Y 31 (green, X) and POP-Y 1 (green, $\bullet$ ) compared to POP- $\mathrm{R}_{\mathrm{Cl}} \mathbf{6}$ (red, $\bigcirc)^{9,35}$ and POP-B 4 (blue, $\left.\square\right)^{23,35}$ and best multiexponential fits.

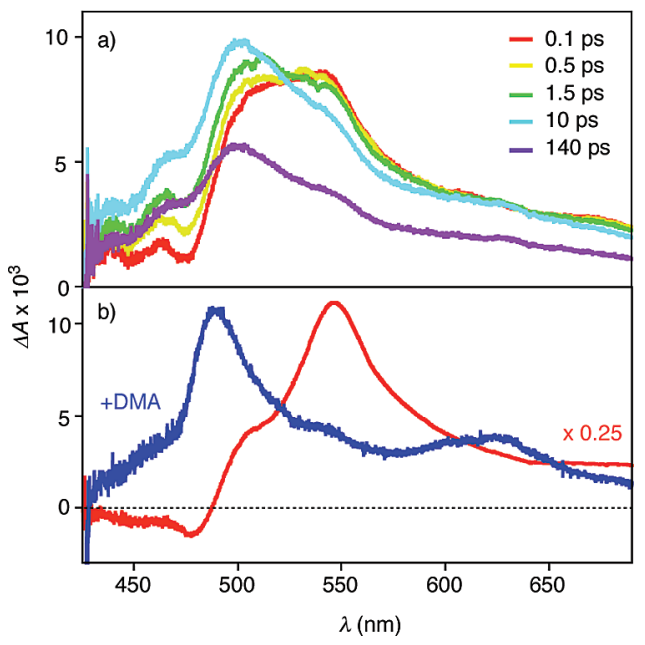

Figure 7. (a) Transient absorption spectra recorded at different time delays after excitation of POP-Y 1 in MeOH and (b) TA spectra recorded after after excitation of monomer Y $\mathbf{3 1}$ with (blue) and without (red) $3 \mathrm{M}$ DMA in $\mathrm{MeOH}$.

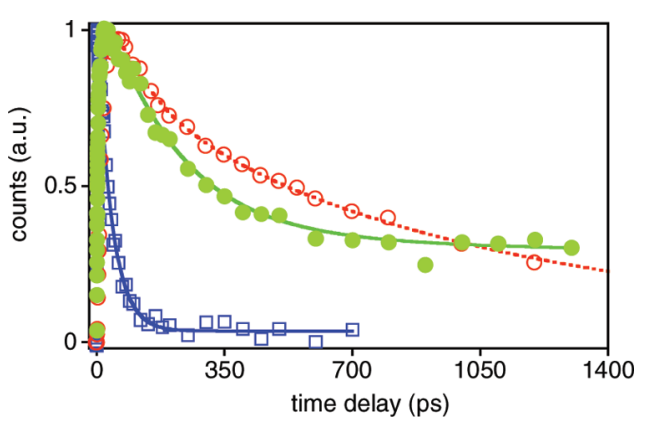

Figure 8. Intensity-normalized time profiles of the CSS population (see text) in the transient absorption of POP-Y 1 (green) with best fit to eq 1 in ref 35 compared to POP-B 4 (blue) and POP- $\mathrm{R}_{\mathrm{Cl}} \mathbf{6}$ (red). ${ }^{35}$

and 10) and cyclic voltammetry and continued until saturation values were reached. The absence of redox waves for $\mathrm{K}_{3} \mathrm{Fe}(\mathrm{CN})_{6}$ demonstrated that the final $\mathrm{Au}-\mathbf{3}$ electrodes do not contain large uncovered areas. The obtained $\mathrm{Au}-\mathbf{3}$ was dipped first into aqueous solutions of the cationic POP-Y propagator $\mathbf{1}$, then into aqueous solutions of the anionic POP-Y propagator 2, and so on (Figure 2).

Comparison with conventionallayer-by-layer(LBL) assembly ${ }^{13,16}$ was essential to verify existence and significance of zipper assembly (Figure 10). For LBL assembly of POP-Y architectures, gold electrodes are covered with lipoic acid $\mathbf{3 5}$ instead of POP-N initiator 3. The obtained $\mathrm{Au}-\mathbf{3 5}$ electrodes have an anionic surface to bind the cationic POP-Y 1, which, according to extensive studies on LBL assembly, ${ }^{13,16}$ should produce an cationic surface to bind the anionic POP-Y dyad 2 . The obtained $\mathrm{Au}-\mathbf{3 5}-\mathbf{1}-\mathbf{2}$ should then bind cationic 1, $\mathrm{Au}-\mathbf{3 5}-\mathbf{1}-\mathbf{2}-\mathbf{1}$ anionic 2, and so on. Beyond the first layer with and without unsubstituted NDI acceptors, the expected differences between zippers $\mathrm{Au}-\mathbf{3}-(\mathbf{1}-\mathbf{2}-)_{n}$ and LBL assemblies $\mathrm{Au}-\mathbf{3 5}-(\mathbf{1}-\mathbf{2}-)_{n}$ are subtle and of supramolecular nature only. Driven by ion pairing and conceivably containing $\pi$-stacks with interdigitating NDIs, POP interdigitiation is not essential for LBL assembly. The main difference with zipper assembly is the presence of intra- and interlayer recognition motifs introduced by initiator 3 and propagated by mismatched rigid-rod scaffolds to produce POP-NDI architectures of higher order.

Photocurrent Generation. Photocurrent generation by POP-Y zipper architectures was evaluated with the gold electrode as electron acceptor, a Pt electrode as cathode, and triethanolamine (TEOA) as electron donor (Figure 9). ${ }^{8,9,33,34}$ The use of dithiothreitol as more powerful (DTT, Figure 9h) or ascorbate as alternative electron donors gave similar results. The slightly stronger $\mathrm{I}^{-}$and hydroquinone gave clearly weaker and very strong but transient photocurrents, respectively. The use of $\mathrm{Co}^{3+}$ (Figure 9i) or the slightly stronger methylviologen acceptor together with TEOA gave less satisfactory results.

Photocurrent generation and termination by POP-Y zippers $\mathrm{Au}-\mathbf{3}-(\mathbf{1}-\mathbf{2}-)_{n}$ was instantaneous, and the obtained currents were as stable as with POP-B and POP- $\mathrm{R}_{\mathrm{Cl}}$ zippers. ${ }^{8,33}$ The photocurrents generated by zipper $\mathrm{Au}-\mathbf{3}-(\mathbf{1}-\mathbf{2}-)_{n}$ increased overall almost linearly with increasing number of layers (Figure $10 \mathrm{a}, \mathbf{O})$.

In early stages, cationic POP-Y 1 produced more significant photocurrent increases, whereas anionic POP-Y 2 could even cause a small decrease. AFM images suggest that these differences could occur by substantial overzipping with cationic POP-Y 1 despite charge repulsion, which then are subsequently displaced by the stronger binding anionic POP-Y 2 (see below). Alternative explanations for these differences include facilitated and hindered electron transfer from TEOA to cationic and anionic zipper surfaces, respectively.

LBL assembly $\mathrm{Au}-\mathbf{3 5}-(\mathbf{1}-\mathbf{2}-)_{n}$ generated clearly less photocurrent (Figure 10a, X). Both zipper and LBL assembly depended strongly on experimental conditions and, importantly, varied for different POP-NDI architectures. Overall, decreasing differences between zipper and LBL assembly with decreasing ionic strength and solvent polarity indicated that contributions

(50) Kalayanasundaram, K.; Kiwi, J.; Grätzel, M. Helv. Chim. Acta 1978, 61, 2720-2730. 


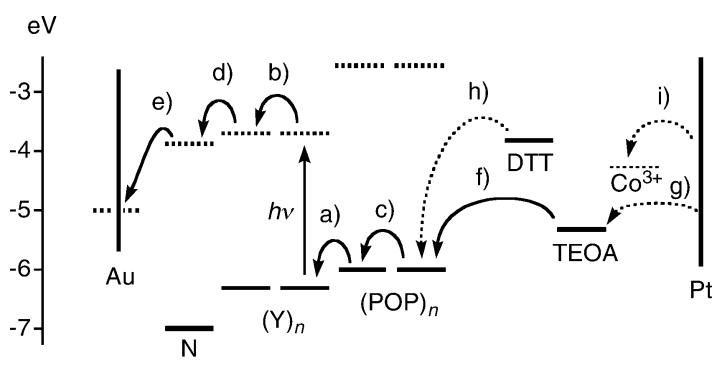

Figure 9. POP-Y photosystems for photocurrent generation. After absorption of light $(h v)$ by yellow NDIs Y, the design envisions (a) PCS by $\mathrm{POP} \rightarrow \mathrm{Y}$ electron transfer (ET), followed by (b) $\mathrm{Y} \rightarrow \mathrm{Y}$, (c) $\mathrm{POP} \rightarrow \mathrm{POP}$, and (d) $\mathrm{Y} \rightarrow \mathrm{N}$ ET along formal OMRG-SHJs, (e) $\mathrm{N} \rightarrow \mathrm{Au}$, (f) TEOA $\rightarrow$ POP, and $(\mathrm{g}) \mathrm{Pt} \rightarrow(\text { decomposed })^{50}$ TEOA ET. Excitation of POP could be followed by energy (or electron) transfer, ${ }^{44}$ that of $\mathrm{N}$ by energy or hole transfer to Y. (h) Use of DTT instead of TEOA gave similar photocurrent. (i) Use of $\mathrm{Co}^{3+}$ together with TEOA gave less photocurrent.

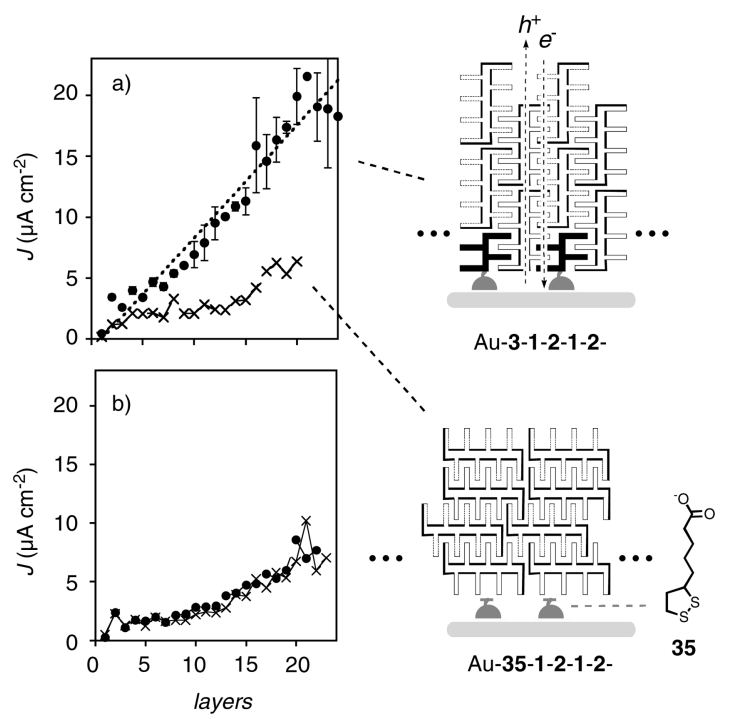

Figure 10. Current-layer profiles of zipper assembly $\mathrm{Au}-\mathbf{3}-(\mathbf{1}-\mathbf{2}-)_{n}$ (0) and assembly LBL Au-35-(1-2- $)_{n}$ (X) with incubation for (a) $48 \mathrm{~h}$ and (b) $24 \mathrm{~h}$ per layer.

from hydrophobic interactions are less specific. Moreover, charge repulsion decreases with increasing ionic strength. The difference between zipper and LBL assembly was detectable only after incubation for $48 \mathrm{~h}$ (Figure 10a). The photocurrents generated by zippers $\mathrm{Au}-\mathbf{3}-(\mathbf{1}-\mathbf{2}-)_{n}$ and LBL assembly $\mathrm{Au}-\mathbf{3 5}-(\mathbf{1}-\mathbf{2}-)_{n}$ after $24 \mathrm{~h}$ of incubation were roughly the same (Figure 10b). This finding confirmed that the assembly of zipper architectures is slower than that of LBL architectures. Together with the previous capping experiments, ${ }^{8}$ the differences found for zipper and LBL assembly confirmed that (a) zipper assembly exists, (b) differs significantly from LBL assembly, and (c) generates more photocurrent than the latter (Figure 10).

The presence of unsubstituted NDI acceptors in POP-N initiators $\mathbf{3}$ is essentially ignored in the discussion of POP-Y photosystems, although it introduces a formal redox gradient in the $\mathrm{e}^{-}$-transporting channel of formal POP-Y/N SHJs. This neglect is appropriate because little difference was found between the corresponding POP- $\mathrm{R}_{\mathrm{Cl}} / \mathrm{N}$ and POP- $\mathrm{R}_{\mathrm{Cl}}$ zippers. ${ }^{33}$

To secure comparative values and validate the approach, the previously reported blue POP-B zippers ${ }^{8}$ were exposed to direct comparison with LBL assembly, as well. Under identically optimized conditions, LBL assembly $\mathrm{Au}-\mathbf{3 5}-(\mathbf{4 - 5}-)_{n}$ failed to generate significant photocurrent, whereas zipper assembly

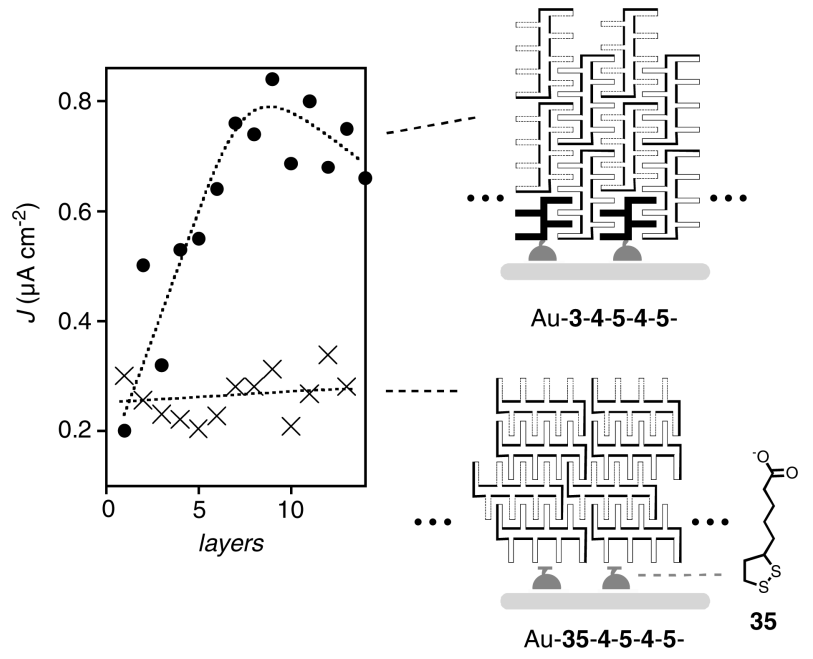

Figure 11. Current-layer profiles of POP-B architectures obtained by zipper assembly $\mathrm{Au}-\mathbf{3}-(\mathbf{4}-\mathbf{5}-)_{n}(\mathbf{O})$ and LBL assembly $\mathrm{Au}-\mathbf{3 5}-(\mathbf{4}-\mathbf{5}-)_{n}$ $(\mathrm{X})$; lines are added to guide the eye.

$\mathrm{Au}-\mathbf{3}-(\mathbf{4}-5-)_{n}$ generated increasing current with increasing thickness until a maximum was reached at around 10 layers (Figure 11). Decreasing photocurrents with zipper assembly beyond the critical 10 layers yielded a bell-shaped $J L$ profile for $\mathrm{Au}-\mathbf{3}-(\mathbf{4}-5-)_{n}$ zippers.

The maximal photocurrent $J_{\max }=0.8 \mu \mathrm{A} \mathrm{cm} \mathrm{cm}^{-2}$ of blue $\mathrm{Au}-\mathbf{3}-(\mathbf{4}-\mathbf{5}-)_{n}$ zippers was clearly inferior compared to the $J_{\max }=20 \mu \mathrm{A} \mathrm{cm}{ }^{-2}$ found for the yellow $\mathrm{Au}-\mathbf{3}-(\mathbf{1}-\mathbf{2}-)_{n}$. Although the significance of this comparison should not be overestimated, this clear difference was consistent with the formation of SHJs with the yellow but not with the blue zippers. Comparable without reservation was the critical thickness of POP zippers. With yellow zippers $\mathrm{Au}-\mathbf{3}-(\mathbf{1}-\mathbf{2}-)_{n}$, photocurrents stopped increasing after around 20 layers of deposition. The critical thickness of blue $\mathrm{Au}-\mathbf{3}-(\mathbf{4}-\mathbf{5}-)_{n}$ zippers was already reached at about 10 layers. The critical thickness of both architectures was clearly better than in related systems. ${ }^{10 a}$ These findings suggested that zipper assembly provides access to higher-order architectures with significant properties. The clearly better critical thickness of yellow compared to blue zippers indicated that the yellow NDIs produce more ordered zipper architectures. This interpretation was in agreement with the stronger $\pi$-stacking expected from more $\pi$-acidic yellow NDIs. Photocurrent saturation occurs either because the zipper stops growing or because electrons and holes start to recombine in thicker architectures before reaching the electrodes. QCM results suggest that the latter applies for the yellow zippers $\mathrm{Au}-\mathbf{3}-(\mathbf{1}-\mathbf{2}-)_{n}$ (see below).

Current-Voltage Curves. Current-voltage $(J V)$ curves were measured to determine short circuit current density $J_{\mathrm{SC}}$, open circuit potential $V_{\mathrm{OC}}$, and the fill factor FF (Figure 12). Fill factors FF relate to the power generated with light, benefit from highly organized surface architectures, ${ }^{5 a}$ and are of critical importance for device efficiency. Minimal fill factors of linear $J V$ curves are $\mathrm{FF}=0.25$, fill factors of optimized organic BHJ solar cell with thick polymer films prepared by top-down methods such as spin coating have a FF $=0.61 .^{2 \mathrm{~b}}$

The $J V$ curve of zipper $\mathrm{Au}-\mathbf{3}-(\mathbf{1}-\mathbf{2}-)_{\mathbf{9}}-\mathbf{1}$ revealed $\mathrm{FF}=$ 0.53 (Figure 12a). This value was higher than the $\mathrm{FF}=0.48$ obtained by LBL assembly $\mathrm{Au}-\mathbf{3 5}-(\mathbf{1}-\mathbf{2}-)_{9}-\mathbf{1}$ (Figure $12 \mathrm{~b}$ ), which confirmed access to highly ordered architectures. ${ }^{5 a}$ FF $=0.53$ found for POP-Y zippers compared also very well with 


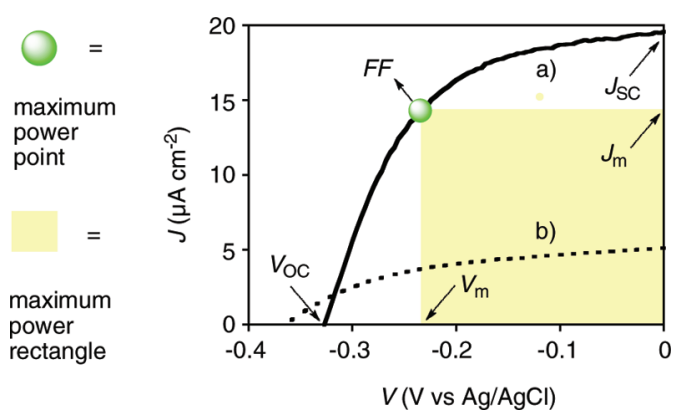

Figure 12. Current - voltage profile of (a) zipper $\mathrm{Au}-\mathbf{3}-(\mathbf{1}-\mathbf{2}-)_{9}-\mathbf{1}$ and (b) LBL Au-35-(1-2-) $)_{9}-\mathbf{1}$ with indication of short circuit current density $\left(J_{\mathrm{SC}}\right)$, open circuit voltage $\left(V_{\mathrm{OC}}\right)$, maximum power rectangle, maximum power point, and fill factor $\mathrm{FF}=$ maximum power $/\left(V_{\mathrm{OC}} \times J_{\mathrm{SC}}\right)=\left(V_{\mathrm{m}} \times\right.$ $\left.J_{\mathrm{m}}\right) /\left(V_{\mathrm{OC}} \times J_{\mathrm{SC}}\right)$.

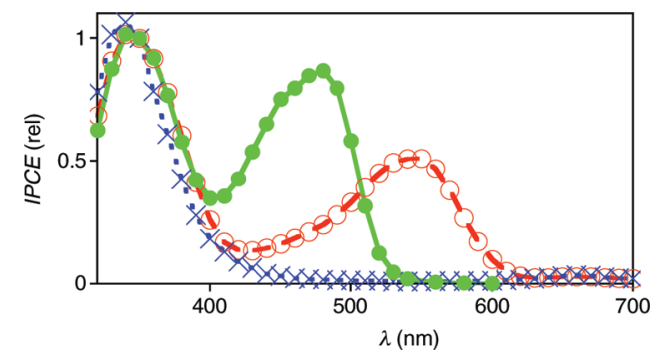

Figure 13. Action spectrum of POP-Y zippers (, green; $\left.\mathrm{Au}-\mathbf{3}-(\mathbf{1}-\mathbf{2}-)_{8}\right)$ compared to the corresponding POP- $\mathrm{R}_{\mathrm{Cl}}(\mathrm{O}$, red) and POP-B zippers (X, blue). ${ }^{9}$ IPCE values are normalized at $350 \mathrm{~nm}$.

$\mathrm{FF}=0.42$ for POP-B zippers (4 layers) ${ }^{9}$ and $\mathrm{FF}=0.49-0.53$ for POP- $\mathrm{R}_{\mathrm{Cl}}$ zippers ( $3-5$ layers). ${ }^{33}$ Comparison of open circuit photocurrents was more appropriate with the relative values accessible in action spectra (see below). Absolute currents and efficiencies are best appreciated considering an up to 280 -fold quenching via energy transfer to gold surfaces. ${ }^{12 a}$

Action Spectra. The action spectrum of zipper $\mathrm{Au}-\mathbf{3}-(\mathbf{1}-$ 2-) 8 revealed a strong peak around $480 \mathrm{~nm}$ (Figure 13, - $)$. Coinciding with the absorption maximum of the yellow NDI, this peak demonstrated that the NDI component in POP-Y zipper architectures generates photocurrent. The ratio $\mathrm{IPCE}_{480} / \mathrm{IPCE}_{350}$ $=0.85$ indicated that the maximal ICPE (incident photon-tocurrent efficiency) accessible around $480 \mathrm{~nm}$ was almost as good as that at high energy. For POP- $\mathrm{R}_{\mathrm{Cl}}$ zippers, the corresponding $\mathrm{IPCE}_{550} / \mathrm{IPCE}_{350}=0.51$ was clearly lower (Figure 13, O). In POP-B zippers, the blue NDI was with $\mathrm{IPCE}_{620} / \mathrm{IPCE}_{350}=0.02$ essentially inactive (Figure 13, X). ${ }^{9}$ The comparably high IPCE of the yellow NDI was in excellent agreement with favorable electron transfer from POP donors to NDI acceptors (Figure 1) in response to light to result in long-lived PCS (Figure 8) and thus the formation of functional SHJs.

Morphology. The POP-Y zipper architectures had exceptionally smooth surfaces (Figure 14). The surface of multilayer zipper $\mathrm{Au}-\mathbf{3}-(\mathbf{1}-\mathbf{2}-)_{3}-\mathbf{1}$ was at least as smooth as uncovered gold surfaces and those of monolayers similar to $\mathrm{Au}-\mathbf{3}$. Constant or decreasing surface roughness with increasing zipper growth was contrary to increasing surface roughness observed with conventional LBL assembly. ${ }^{13}$ The final surfaces of advanced zippers were clearly smoother than those of LBL and top-down spin-coated BHJ photosystems. ${ }^{2,3,13}$ For example, root-mean-square (rms) roughness as large as 2.6, 3.2, and 4.7 $\mathrm{nm}$ has been reported for the LBL films with 1,5 , and 11 bilayers, respectively. ${ }^{13 \mathrm{c}}$ Low surface roughness has been
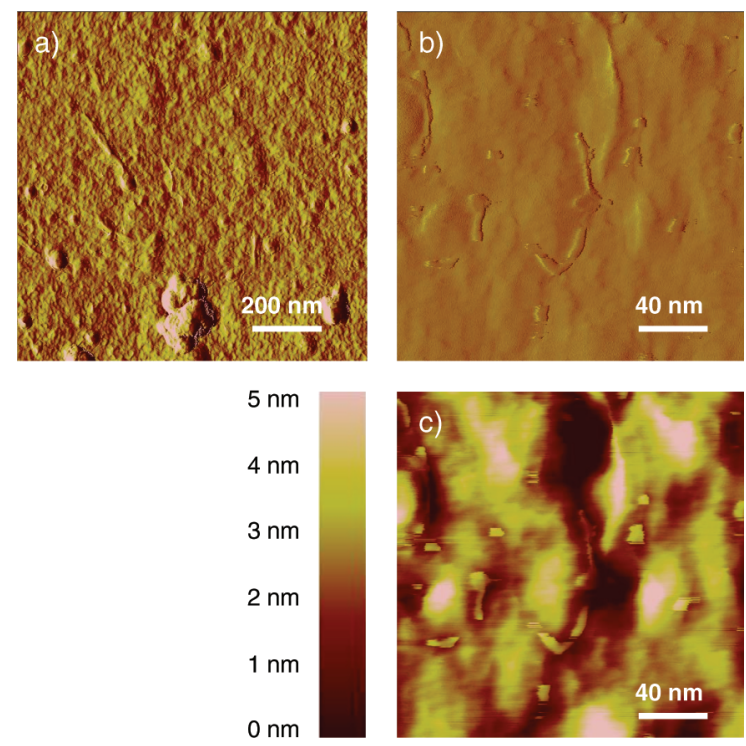

Figure 14. Tapping mode AFM overview (a) and magnified (b,c) amplitude $(\mathrm{a}, \mathrm{b})$ and height images $(\mathrm{c})$ of multilayer zippers $\mathrm{Au}-\mathbf{3}-(\mathbf{1}-\mathbf{2}-)_{3}-\mathbf{1}$.
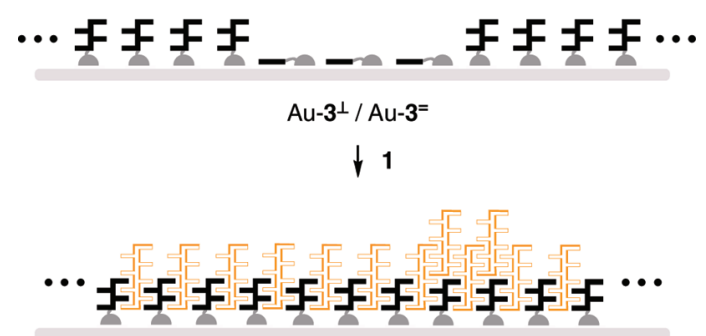

Au-3-1 / Au-3-1-1

$\downarrow 2$

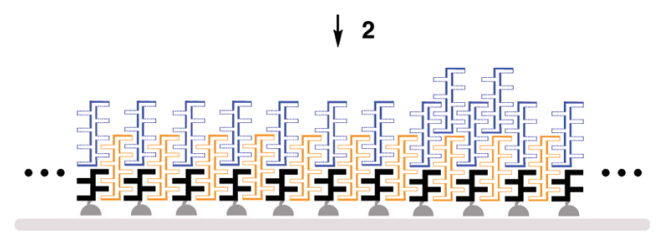

Au-3-1-2 / Au-3-1-2-2

$\downarrow 1$

Figure 15. Possible mechanisms of mixed zipper architectures integrating overzipped domains.

proposed to be the key to significant function in molecular optoelectronics, including high photovoltaic efficiency. ${ }^{2}$

Atomic force microscopy (AFM) images further revealed occasional clumps. They already occurred with monolayers similar to $\mathrm{Au}-\mathbf{3}$ and are of unknown origin, particularly considering that the layers were grown on common, piranhacleaned gold surfaces without special purity precautions.

Presumably more important, AFM images also revealed sharp steps of $1.5 \mathrm{~nm}$ height between lower and higher domains. With $\mathrm{Au}-\mathbf{3}$, such steps may occur at the edges of "open", high and soft domains where initiators stand vertically on the surface (i.e., $\mathrm{Au}-3^{\perp-}$ ) and "closed", low and hard domains where initiators lay flat on the surface (i.e., $\mathrm{Au}-\mathbf{3}^{=}$, Figure 15). Addition of cationic propagators 1 to mixed $\mathrm{Au}-3^{\perp}-/ \mathrm{Au}-\mathbf{3}^{=}$monolayers could then cause the laying initiators to stand up to give a homogeneous, soft and open bilayer $\mathrm{Au}-\mathbf{3}-\mathbf{1}-$ (Figure 15).

With $\mathrm{Au}-\mathbf{3}-\mathbf{1}$ and higher $\mathrm{Au}-\mathbf{3}-(\mathbf{1}-\mathbf{2}-)_{n}-\mathbf{1}$ zippers, the occasionally occurring $1-2 \mathrm{~nm}$ higher domains could then 


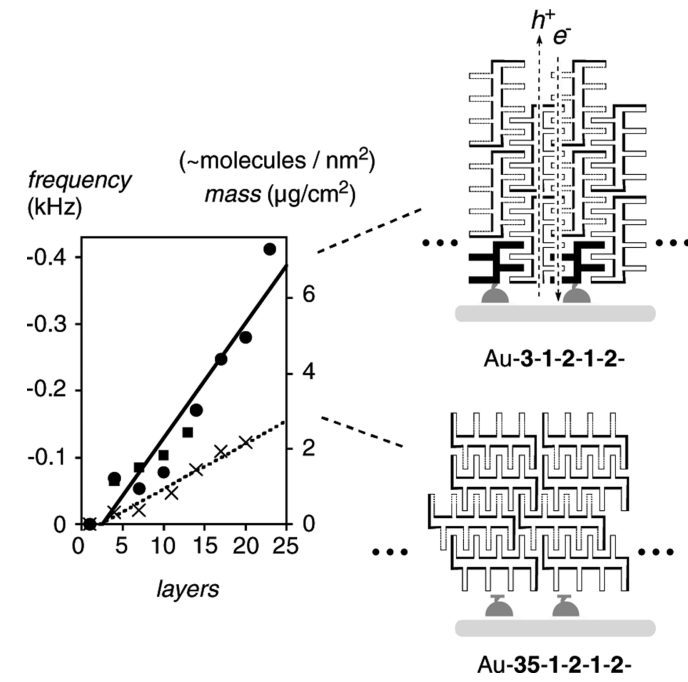

Figure 16. QCM frequencies (with linear curve fit) as a function of the number of theoretical layers of zipper assembly $\mathrm{Au}-\mathbf{3}-(\mathbf{1}-\mathbf{2}-)_{n}(\mathbf{C}, \mathbf{\square}$ and LBL assembly $\mathrm{Au}-\mathbf{3 5}-(\mathbf{1}-\mathbf{2}-)_{n}(\mathrm{X})$.

originate from additional cationic propagators $\mathbf{1}$ that zip up weakly despite charge repulsion. Addition of anionic propagators 2 would then displace these weakly bound overzipped cationic propagators 1 to afford $\mathrm{Au}-\mathbf{3}-\mathbf{1}-\mathbf{2}$ and higher $\mathrm{Au}-\mathbf{3}-(\mathbf{1}-$ $\mathbf{2}-)_{n}$ zippers with some overzipped $\mathrm{Au}-\mathbf{3}-\mathbf{1}-\mathbf{2}-\mathbf{2}$ to account for the $1-2 \mathrm{~nm}$ higher planes. Stronger photocurrents obtained after addition of cationic propagators $\mathbf{1}$ could then suggest that overzipping is more likely with $\mathbf{1}$ than with anionic propagators 2. This interpretation appears meaningful considering acidity and basicity of the involved anions and cations.

Quartz Crystal Microbalance. The mass deposited by zipper assembly of POP-Y architectures was determined electromechanically with a quartz crystal microbalance (QCM) (Figure 16). The mass deposited by zipper assembly clearly exceeded that deposited by LBL assembly. This result suggested that the differences found for photocurrent generation by zipper and LBL assembly originate to a good part from the different amounts deposited per layer (Figure 10a vs 16). Nevertheless, QCM data demonstrated continued deposition in the LBL assembly, in contrast to the saturation behavior found in the photocurrent generation after about 4 layers. Better charge mobility with higher long-range order in zipper assembly is likely to contribute to the found strong relative photocurrent, as well.

In contrast to photocurrent generation, zipper assembly did not show saturation in the QCM signal (Figure 10a vs 16). This lack of saturation indicated continuous growth of the surface assembly. Photocurrent saturation in $\mathrm{Au}-\mathbf{3}-(\mathbf{1}-\mathbf{2}-)_{n}-\mathbf{1}$ zippers thus occurred because charges start to recombine before reaching the electrodes and not because POP-Y zippers stop growing. This finding revealed that the critical thickness of $\mathrm{Au}-\mathbf{3}-(\mathbf{1}-\mathbf{2}-)_{n}-\mathbf{1}$ is reached around $\sim 20$ layers (i.e., $\left.\mathrm{Au}-\mathbf{3}-(\mathbf{1}-\mathbf{2}-)_{9}-\mathbf{1}, \sim 30 \mathrm{~nm}\right)$. Comparable systems in the literature have inferior critical thickness. ${ }^{10 a, 13 \mathrm{c}}$ The important critical thickness found thus confirmed that the long-range organization of POP-Y zipper architectures is extraordinary and matters for function.

\section{Conclusions}

The characteristics of the here introduced yellow POP-Y photosystems are outstanding. Compared to the blue and red architectures as well as related LBL systems, yellow zippers excel with optoelectronic matching, long-lived photoinduced charge separation, strong $\pi$-acidity, strong photocurrents, as well as significant critical thickness and smooth surfaces.

The consistency of results with the complete primary color series of POP-Y, POP- $\mathrm{R}_{\mathrm{Cl}}$, and POP-B hybrids is remarkable. The decreasing HOMO and LUMO energies from blue over red to yellow NDIs coincide with increasingly facile electron transfer from POP donors to excited NDI acceptors. This increasingly favorable rod-stack PCS correlates perfectly with increasing photocurrent generation by blue $<$ red $<$ yellow NDI chromophores in the action spectra of their POP-NDI architectures. Increasing $\pi$-acidity with blue $<$ red $<$ yellow NDIs is expected to strengthen $\pi$-stacking in zipper assemblies, increase charge mobility, and organize zipper architectures. These trends conceivably account for excellent critical thickness, fill factors, and surface smoothness of POP-Y architectures.

These results demonstrate that the here reported insights from direct comparison with LBL assembly, QCM, AFM, and molecular modeling are essential to understand zipper assembly. They identify the new POP-Y zipper architectures as ideal for the creation of optoelectronic devices including OMARG-SHJs. The availability of the primary color collection of POP-NDI zippers is particularly important because it suffices, in principle, to already build mixed OMARG-SHJ architectures that absorb most of the visible light and have an oriented "blue $\rightarrow$ red $\rightarrow$ yellow" redox gradient in the $\mathrm{e}^{-}$-transporting channel (Figure 1). With access to multicolor redox gradients in the $\mathrm{e}^{-}$-transporting channel secured, we currently try to better integrate red and blue NDIs as well as to install redox gradients in the $\mathrm{h}^{+}$transporting channel. Linear conjugated oligomers with high HOMO levels and topologically matching repeat distances such as oligophenylethynyls (OPEs) or oligothiophenes are currently envisioned to solve both problems. In parallel, we try to develop access to surfaces other than gold to avoid quenching from plasmon surface resonance and thus increase zipper efficiency.

Acknowledgment. We thank D.-H. Tran and L. Maffiolo for contributions to synthesis, D. Jeannerat, A. Pinto, and S. Grass for NMR measurements, P. Perrottet, N. Oudry, and G. Hopfgartner for MS, the Swiss National Supercomputing Center (CSCS) in Manno for CPU time, and the University of Geneva, the Swiss NSF, and the Nanotechnology network Nanoned for financial support.

Supporting Information Available: Experimental details. This material is available free of charge via the Internet at http:// pubs.acs.org.

JA9030648 